\title{
Effects of SNS Characteristics on SNS Engagement and Consumer Brand Engagement
}

\author{
Byung-Kwan $\mathrm{CHO}^{1}$, Hyang-Sook SHIN ${ }^{2}$ \\ Received: April 8, 2020 Revised: May 15, 2020 Accepted: May 30, 2020.
}

\begin{abstract}
Purpose: Social Network Sites(SNS) have been grown up as a public communication channel consumer frequently participate in. Most of food service brands are utilizing social media for advertising recently. As a result of SNS marketing, food service brands anticipate positive outputs from SNS engagement and consumer brand engagement so that we need to verify structural relationship among SNS characteristics, SNS engagement and consumer brand engagement. Research design, data, and methodology: This study identifies that SNS characteristics have effects on SNS engagement and examines relationship between SNS engagement and behavioral engagement. We conceptualize SNS characteristics as information quality, hedonic level and interaction. Furthermore, SNS engagement is composed of SNS participation, positive word of mouth(WOM). In order to verify the purposes of this research, research model and hypotheses were developed. All constructs were measured with multiple items developed and tested in the previous studies. Sample data were collected from 433 online survey panels and analyzed by using SmartPLS 3.2.9. Result: The findings of this research are as follows. First, information quality is positively related with SNS participation. Hedonic level and interaction have impacts on SNS participation and positive WOM respectively. Second, SNS participation has positive effects on positive WOM. Third, both SNS participation and WOM influence behavioral engagement respectively. Conclusions: The implications demonstrate that SNS characteristics such as information quality and hedonic level and interaction exert effects for consumer to participate in SNS brand page. Meanwhile, hedonic level and interaction influence on positive WOM but information quality doesn't. SNS participation and positive WOM affect consumer to engage in specific brand behaviorally as well. Therefore, food service brand marketer is required to manage SNS information quality and hedonic level and interaction among members to encourage SNS participation and positive WOM. As SNS participation and positive WOM increases behavioral engagement of consumer, marketer needs to incentivize SNS participation and look after situation of positive WOM and respond swiftly.
\end{abstract}

Keywords: SNS characteristics, SNS engagement, SNS participation, positive WOM, behavioral engagement

JEL Classification Code: M30, M31, M37

\section{1. 서론}

SNS 는 인터넷의 비약적인 발전과 함께 많은 소비자들이 참여하는 대중적인 커뮤니케이션 채널로 성장하였다. 소셜 미디어는 마케터가

1 First Author, Doctoral Candidate, School of Business, Sejong University, Seoul, Korea, Email: jo423@naver.com

2 Corresponding Author, Chairman, Senior Venture Association, Seoul, Korea, Email: Ubooy@hanmail.net

(c) Copyright: Korean Distribution Science Association (KODISA)

This is an Open Access article distributed under the terms of the Creative Commons Attribution Non-Commercial License (https://creativecommons.org/licenses/by-nc/4.0/) which permits unrestricted non-commercial use, distribution, and reproduction in any medium, provided the original work is properly cited.
온라인을 통해 외식 소비자에게 편리하게 접근할 수 있는 경로를 제공하여 선호되므로(Bilgihan, Peng, \& Kandampully, 2014), 대부분의 외식업체가 소셜 미디어를 광고의 목적으로 사용하고 있으며(Kim, Koh, Cha, \& Lee, 2015), 유튜브, 트위터, 구글 플러스, 페이스북, 인스타그램 등의 SNS 는 외식산업의 필수적인 마케팅 채널로 진화하였다DiPietro, Crews, Gustafson, \& Strick, 2012; Kwok \& Yu, 2013; Sparks \& Bradley, 2017). 또한 SNS 는 주요한 정보 전달 플랫폼인 동시에 핵심적 정보 원천이므로 SNS 가 제공하는 정보의 질적 측면에 대한 연구가 필요하다. 온라인 브랜드 커뮤니티에서 소비자 참여는 브랜드와 관련된 정보품질에 달려있다(Dessart, Veloutsou, \& Morgan-Thomas, 2015; Dholakia, 
Blazevic, Wiert, \& Algesheimer, 2009). 한편 정보품질 이외에 SNS 이용을 통해 얻어지는 즐거움과 커뮤니티 회원들 간의 관계가 SNS 특성으로 고려될 필요가 있다. 소비자는 휴식과 즐거움을 추구하고 브랜드에 대한 재미있는 콘텐츠를 읽고, 게임을 하며, 음악을 듣고, 비디오를 보기 위해 SNS 브랜드 페이지를 이용한다(Martins \& Patńíi, 2013; Whiting \& Williams, 2013).

또한 관계적 측면에서 SNS 는 회원 간의 높은 사회적 상호작용을 발생시키고 회원을 연결시키는 도구가 되면서 소셜 미디어의 이용이 급증하고 있다(Kaplan \& Haenlein, 2010).

정보시스템 성공모델(Delone \& Mclean, 1992)은 정보시스템의 속성인 정보품질과 시스템 품질이 시스템의 이용과 만족 그리고 성과에 미치는 영향을 연구하였으나, 정보품질 외에 다양한 정보 특성이 소비자의 SNS 참여에 미치는 영향을 종합적으로 분석한 연구는 부족하다. 따라서 본 연구는 SNS 의 특성을 정보품질 특성, 쾌락적 특성, 관계 특성으로 분류하고 이것이 소비자의 SNS 참여에 어떤 영향을 미치는지 검증하고자 한다.

한편 소셜 미디어 상의 참여는 온라인 마케팅 플랫폼에서 소비자의 콘텐츠 공유, '좋아요'와 댓글 등을 실행하는 과정이다(Leung, Bai, \& Stahura, 2015; Lim, Hwang, Kim, \& Biocca, 2015). Men and Tsai(2013)는 소셜미디어에 대한 대중의 참여를 능동적인 양방향 대화, 활동, 온라인 추천 등의 계층적 행동 단계를 가진 행동적 구성개념으로 정의하였다.

소비자 브랜드 참여는 브랜드와의 상호작용에서 인지적, 감정적, 행동적 수준으로 측정되는 소비자의 브랜드와 관련된 마음의 상태이다(Hollebeek, 2011). 소비자 브랜드 경험과 소비자 관여도는 브랜드 참여에 유의한 영향을 미치고, 브랜드 참여는 브랜드 관계 구축에 영향을 미친다(Touni, Km, Choi, \& Ali, 2019).

한편 SNS 참여가 SNS 활동과 긍정적 구전으로 구성되며, 브랜드 태도에 미치는 영향은 검증되었으나(Algesheimer, Dholakia, \& Hermann, 2005; Zheng, Cheung, Lee, \& Liang, 2015), SNS 참여의 구성요인 간의 관계를 규명하고 소비자의 SNS 참여가 실질적으로 브랜드에 대한 행동적 참여에 미치는 영향에 대한 연구는 희박하다. 또한 실무적으로 많은 외식업체가 SNS 를 이용하여 소비자의 참여를 제고하는 마케팅 성과를 창출하기 위해 노력하고 있지만, 어떻게 SNS 를 통해 기업의 운영을 강화하는지 모른다(DiPietro et al, 2012).

본 연구는 이러한 문제의 해결을 위한 단초를 제시하기 위해 Algesheimer et al, (2005)의 연구를 기반으로 다양한 SNS의 특성이 소비자의 SNS 참여에 미치는 영향을 검증하고, 행동적 참여를 SNS참여의 결과 요인으로 가정하여 SNS 참여가 소비자 브랜드 참여에 미치는 영향을 조사하였다. 또한 외식업체가 SNS 특성을 활용하여 소비자의 SNS 참여를 제고하고 긍정적인 브랜드 행동을 유인하는 마케팅 전략을 수립하는데 도움이 되는 이론적, 실무적 시사점을 논의하고자 한다.

\section{2. 이론적 고찰}

\subsection{SNS 정보품질 특성}

정보시스템 성공 모델(Information System success mode)에 의하면, 정보품질과 시스템 품질은 정보시스템의 이용 및 이용자의 만족과 긍정적 관계가 있고 결과적으로 개인 및 조직의 성과에 영향을 미친다(DeLone \& Mdean, 1992). 정보품질 차원은 정보시스템 이용자에 대한 연구에 빈번히 이용되나 본 연구에서는 소비자의 SNS 참여에 영향을 주는 요인으로 사용되었다.

정보품질을 다차원으로 개념화하고 측정하는 다수의 모델이 존재한다 (Miller, 1996; Zmud, 1978). 정보품질은 정확성, 적시성, 완전성, 형식, 접근가능성, 양립성, 안전성, 타당성 등 정보 이용자가 정보품질에 대해 가지는 욕구의 정도이다(Miller, 1996). 따라서 SNS 정보품질은 SNS 를 통해 얻은 정보에 대한 지각된 품질이라고 할 수 있다. 또한 정보품질은 정보만족, 정보시스템 이용태도, 정보시스템 이용의도, 시스템 수용과 이용에 대한 중요한 예측 요인이다(Delone \& Mdean, 2003; Ghasemaghaei \& Hassanein, 2015; Nicolaou, Ibrahim, \& Van Heck, 2013; Wixom \& Todd, 2005).

따라서 본 연구는 외식업체의 SNS 가 제공하는 정보의 정확성, 신뢰성, 적시성, 관련성, 완전성 정도로 정보품질을 정의하였다. 정보의 정확성은 정보가 명확하고, 객관적일 뿐만 아니라 의미 있고 믿을 만한 것이라는 개념이다(Wand \& Wang, 1996). 신뢰성은 이용자가 정보의 내용이 믿을 만하여 정보에 대한 확신을 가지고 행동하는 것을 의미하며 정보를 신뢰하는 SNS 이용자는 정보를 획득하기 위한 시간 투여로 인해 SNS 이용에 대해 긍정적인 태도를 가진다(Koohikamali \& Sidorova, 2017).

정보의 적시성은 정보가 충분히 업데이트 되는 정도이다Wang \& Strong, 1996). 온라인 리뷰에서 정보의 적시성은 지각된 정보 유용성과 긍정적으로 관련되어 있다(Cheung, Lee, \& Rabjohn, 2008). 정보의 관련성은 이용자에게 제공되는 정보의 적절성이며, 종종 이용자의 관심에 따라 달라진다(De Choudhury, 2011). 정보의 완전성은 정보의 충분한 폭과 깊이를 말하고(Wang \& Strong, 1996), 매우 중요한 정보품질의 요소의 하나로(Sullivan, 1999) 정보 이용자의 지각된 유용성과 정보 수용에 긍정적 영향을 미친다(Cheung et al, 2008). 따라서 정보품질은 SNS 참여에 영향을 미칠 가능성이 높고 정보품질 향상 방안은 매우 중요한 SNS 프로모션의 관리 요소가 될 수 있을 것이다.

\subsection{SNS 쾌락적 특성}

쾌락적 가치는 소비자가 소비경험을 통해 가지게 되는 환상적, 감정적, 감각적 가치로 정의되며, 환기, 자유, 환상의 충족, 일상탈출 등의 경험이다(Babin, Darden, \& Griffin, 1994). 브랜드에 참여하는 이유로 즐거움, 
사회적 영향, 정보의 탐색과 신뢰 등이 있다. 이 중 즐거움은 소비자의 SNS 이용과 관련한 주요한 동기 중 하나이다(de Vries, Gensler, \& Leeflang, 2012; Rohm, Kaltcheva, \& Mine, 2013). 정보의 즐거움은 정보의 소비가 기쁘고, 즐겁고, 재미있게 느겨지는 정도로 측정되며 SNS 정보가 즐거움을 제공한다면 그 정보는 가치가 있다(Lee, Lee, Kwon, Jeong, \& Hur, 2019 이용자가 SNS 를 통해 쾌락적 가치를 얻으면 이용자는 SNS 참여에 대해 긍정적인 태도를 갖게 된다(Koohikamali \& Sidorova, 2017).

이와 유사한 개념으로 흥미는 정보가 재미있다고 인식되는 정도이다. 여행 블로그에서 콘텐츠가 주는 흥미가 여행 목적지에 대한 방문의도에 영향을 미친다(Chen, Shang, \& Li, 2014). 이와 같이 특정한 온라인 정보가 재미있다고 인식되면, 이용자는 소셜 미디어에서 더 많은 정보를 읽고 공유하는데 시간을 사용한다(Kim, Lee, Shin, \& Yang, 2017). 그러므로 본 연구는 외식업체 SNS 이용자가 경험하는 즐거움, 기쁨, 흥미, 재미의 정도로 SNS 쾌락적 특성을 정의하였다. 결론적으로 소비자는 정보가 매력적이고 흥미롭다면 그 상품과 브랜드 페이지를 좋아하는 경향이 있다(Coulter \& Roggeveen, 2012). 그러므로 SNS 쾌락적 특성은 소비자들의 SNS 참여를 향상시킬 수 있는 좋은 수단을 제공하게 될 것이다.

\subsection{SNS 관계 특성}

사회적 조직(Sodal Organization)은 커뮤니티 회원 사이에 상호작용을 구축, 촉진, 제한하는 커뮤니티 내의 가치, 규범, 절차와 행동규범의 집합으로 정의된다(Manani, Martin, \& Bowen, 2003).

사회적 상호작용 관계는 사회적 자본의 구조적 차원의 하나로 사회적 조직이론에서 사용되었다(Lin\& Lu, 2011; Nahapiet \& Ghoshal, 1998). 사회적 상호작용 관계는 사람들 간의 대인관계를 의미하고(Varey, 2008; Wang \& Chen, 2012), 정보와 자원이 유통되는 채널이며(Tsai \& Ghoshal, 1998), 사람 간의 관계 강화를 위해 사용된 시간의 양, 감정적 강도, 친근함, 호혜적 서비스의 정도로 측정된다(Granovetter, 1973). 따라서 온라인 커뮤니티 회원 간의 사회적 상호작용 관계는 사용된 시간과 관계의 빈도로 측정된다Wang \& Chen, 2012). 온라인 커뮤니티와 유사한 특성이 있는 SNS 에서의 사회적 상호작용 관계도 SNS 회원 간의 커뮤니케이션 빈도와 친근정도로 측정된다Wang \& Chen, 2012).

따라서 본 연구는 SNS 관계 특성을 외식업체 SNS 이용자 간의 관계의 강도와 빈도의 정도로 정의하였다. SNS 에서의 사회적 상호작용 관계는 가족, 친구, 지인들이 관계를 유지하고, 외부의 사람과 온라인에서 관계를 구축하는 것을 지원하고(Blattberg \& Deighton, 1991; Stromer-Galley, 2000), SNS 회원들 간의 신뢰와 관계 몰입, 공유된 가치, SNS 지속 이용의도에 긍정적인 영향을 준다(Lin \&lu, 2011; Wang \& Chen, 2012). 따라서 소비자들의 SNS 참여 활동은 관계적 상호작용을 통하여 많이
이루어지고 그 결과 구매 활동에도 긍정적인 영향을 미칠 수 있을 것으로 기대된다.

\subsection{SNS 참여}

사회적 교환이론(Social Exchange Theory)에 의하면, 인간의 의사결정과 행동은 비용과 보상의 비교를 통해 이루어지며 궁극적으로 자기이익을 지향한다(Blau, 1964). SNS 이용자는 SNS 커뮤니티에서 이익을 얻을 수 있다고 생각할 때 SNS 참여와 SNS 홍보 활동에 동기 부여되고 경제적 인센티브가 주어질 때 더욱 적극적으로 참여하거나 정보를 공유하려고 한다(Hennig-Thurau, Gwinner, Walsh, \& Gremler, 2004).

커뮤니티 참여는 커뮤니티 활동과 긍정적 구전활동으로 구성된 개념으로 볼 수 있고, 커뮤니티 참여는 몰입을 통해 브랜드 충성도에 영향을 미친다(Algesheimer et al, 2005; Zheng, Cheung, Lee, \& Liang, 2015). 또한 온라인 커뮤니티 활동은 커뮤니티의 성공을 위한 필수 요소이며, 지속적인 커뮤니티 참여는 집단의 공동목표를 달성하는데 도움을 준다(Bagozi \& Dholakia, 2006ª).

Koh and Kim(2004)은 가상 커뮤니티에서의 활동을 연구하기 위해 1) 다른 커뮤니티 회원과의 상호작용 동기, 2) 가상 커뮤니티를 활성화시키기 위한 상호작용 3) 커뮤니티의 다른 회원을 위한 유용한 정보 제공 4) 커뮤니티에서 개인적인 메시지를 올리고 응답하는 즐거움 등의 측정을 제안하였다.

또한 소비자의 기업 SNS 페이지에 대한 참여는 기업의 진실성과 기업의 투명성, 기업과 대중간의 관계, 그리고 소비자의 옹호에 긍정적 영향을 미치므로 소비자의 SNS 참여를 활용하여 소비자와 건실한 관계를 구축하는 것은 중요하다(Men \& Tsai, 2014). 본 연구는 SNS 참여의 하위차원을 SNS 활동과 긍정적 구전활동으로 구분하여 소비자 브랜드 참여에 미치는 영향을 검증하고자 한다.

\subsubsection{SNS 활동}

온라인에서의 활동은 웹사이트와 이용자가 능동적으로 상호작용하는 정도로 측정된다(Huang, 2003). 또한 소비자는 기업의 SNS 페이지에서 상품 또는 서비스에 대한 댓글 달기, 질문하기, 지지 표명, 제안, 기업의 포스트를 다른 온라인 지인과 공유하기 등을 통해 활동한다(Men \& Tsai, 2014).

온라인 사이트에서의 커뮤니티 활동은 다른 온라인 소비자와 상호작용하는 것을 촉진한다. 온라인 브랜드 커뮤니티에 참여하는 것은 커뮤니티 멤버들과 협력하고 상호작용하고자 하는 소비자의 내재적 동기이다(Algesheimer et al, 2005). 한편 소비자 참여는 동기적 원천에서 기인하여 구매를 넘어서는 브랜드와 기업에 대한 고객의 행동적 표시로 브랜드에 대한 확신과 신의, 자부심, 열정을 내포한다(McEwen, 2004). 
SNS는 대중이 참여하여 관계를 구축하거나 강화하는 중요한 도구로 인식된다(Sashi, 2012). 그러므로 소비자가 기업의 SNS 페이지에 참여하는 것은 기업과의 관계를 구축하고 유지하는 활동으로 볼 수 있다.

Muntinga, Moorman, and Smit(2011)는 소비자의 참여 수준을 등급화 및 유형화하였으며 가장 낮은 수준의 참여를 콘텐츠를 소비하는 유형으로, 중간 수준을 콘텐츠에 공헌하는 유형으로, 가장 높은 수준을 콘텐츠를 창조하는 유형으로 분류하였다. 또한 온라인 커뮤니티에서 포스팅은 효과적인 커뮤니케이션이며 소비자로 하여금 사회적인 존재감을 느끼게 한다(Awad and Ragowsky, 2008).

그러므로 본 연구는 외식업체 SNS 이용자가 대화, 협력, 공유 등을 통해 SNS 에 참여하는 정도로 SNS 활동을 정의하였다. SNS 와 같은 가상의 커뮤니티에서의 활동은 커뮤니티의 지속적 발전을 위해 중요하다(Casaló, Flavian, \& Guinalíu, 2007).

\subsection{2. 긍정적 구전}

구전은 브랜드에 대한 소비자 충성도를 측정하는 요인으로 폭 넓게 이용되었다(Anderson, 1998; Cheng, Lam, \& Hsu, 2006). 구전은 브랜드, 상품 또는 서비스와 이전 구매 경험에 대한 의도된 비공식적 커뮤니케이션이며(Anderson, 1998), 개인적 구전은 보통 서로 아는 소비자 간의 구두 커뮤니케이션을 의미한다(Allsop, Bassett, \& Hoskins, 2007; Maxham, 2001; Meuter, McCabe, \& Curran, 2013).

또한 소비자는 구전을 통해 기업에 대한 중요한 정보를 다른 소비자에게 제공하여 다른 소비자의 구매 또는 철회 결정을 도와준다(Lundeen, Harmon, \& McKenna-Hamon, 1995; Zeithaml, Berny, \& Parasuraman, 1993). 구두 커뮤니케이션은 전화 또는 대면 등의 방법이 이용되며 개인적 구전의 $75 \%$ 는 대면으로 발생한다(Keller, 2007; Keller, \& Fay, 2009). 반면 온라인 구전은 인터넷 기반의 커뮤니케이션으로 보통 글을 통해 발생한다(Dellarocas, 2003; Lee \& Youn, 2009; Steffes \& Burgee, 2009).

Woisetschläger, Harteb, and Blut(2008)는 긍정적 구전은 소비자가 호의적으로 상품과 브랜드를 다른 잠재 고객에게 추천할 가능성이라고 하였다. 또한 가상의 커뮤니티에서의 긍정적 구전은 커뮤니티를 비회원에게 추천하려는 의도이며, 추천은 새로운 회원의 가입을 유도하여 장기적으로 커뮤니티가 영속할 수 있게 하므로 중요하다(Algesheimer et al, 2005).

커뮤니티에서 긍정적 구전은 다른 사람에게 커뮤니티 추천하기, 커뮤니티 회원의 혜택에 대해 이야기하기, 비회원을 가입시키기 위해 초대하기, 커뮤니티 비판에 대해 커뮤니티의 긍정적 측면 강조하기 등의 요소를 포함하며 커뮤니티의 회원은 그들의 가까운 지인들에게 더욱 빈번하게 커뮤니티를 홍보한다(Koh \& Km, 2004).

따라서 본 연구는 외식업체 SNS 이용자가 다른 사람들에게 SNS 를 추천하고 가입을 권유하며 혜택을 소개하는 정도로 긍정적 구전을
정의하였다. 구전은 시장에 영향을 미치는 가장 강력한 힘 중에 하나이며(Bansal \& Voyer, 2000), 또한 구전이 영화(Mizerski, 1982)와 자동차(Swan \& Oliver, 1989) 등의 판매를 증가시키는 것으로 밝혀졌다. 소비자의 선택이 통상적으로 구전에 영향을 받으며, 특히 구전이 중대한 구매에 영향을 미친다는데 중요성이 있다(Lutz \& Reilly, 1973).

개인적 정보원천이 태도에 긍정적 영향을 미치는 반면 상업적 정보원천과 일반적 정보원천은 태도와 관계가 없으며 상업적 정보원천은 즐거움을 매개로 태도에 영향을 미친다Kang, Yang, \& Lee, 2018). 소비자는 기업이 제공하는 광고 캠페인과 같은 상업적 정보원천보다 다른 소비자와 같은 비공식적이고 개인적인 원천에 의지하기를 선호한다(Bansal \& Voyer, 2000). 구전이 다른 원천 보다 믿을 만하고 신뢰할 수 있다고 평가하기 때문이다(Day, 1971).

\section{5. 행동적 참여}

참여는 중요한 사람이나 브랜드와의 상호작용을 통해 발생되는 소비자의 감정적 상태이다(Brodie, Hollebeek, Juní, \& Ilić, 2011). 또한 소비자 브랜드 참여는 소비자가 브랜드와의 관계를 발전시키기 위해 지속적인 브랜드와의 상호작용을 통해 나타나는 행동적 표현이며, 관심, 열정적 활동, 사회적 관계로 구성된 다차원적 개념이다 $N_{N}$ vek, Beatty, Dalela \& Morgan, 2014).

Keller(2013)는 브랜드 참여를 거시적 관점과 미시적 관점으로 구분하여 거시적 관점에서 참여에 사용된 소비자 자원의 유형을 연구하는 한편 미시적 관점에서는 브랜드 정보의 수집, 브랜드 마케팅 참여, 타인과의 상호작용 등 브랜드에 관련된 구체적 행동을 측정하였다.

한편 Hollebeek, Glynn, and Brodie(2014)는 소비자 브랜드 참여를 브랜드 또는 기업에 대한 인지적, 감정적, 행동적 반응으로 정의하고 이러한 본질에 상응하는 인지적 과정, 감정, 활성화 차원을 제안하였다. 첫째, 인지적 과정은 소비자가 특정한 브랜드를 생각하는 수준으로 정의되었으며, 둘째, 감정은 감정적 소비자 참여를 의미하고 브랜드에 대한 애정의 정도로 정의되었고 셋째, 활성화는 행동적 소비자 브랜드 참여를 의미하고 소비자가 브랜드에 쏟은 열정, 노력, 시간의 수준으로 정의되었다.

최근의 연구는 행동적 소비자 참여에 관심을 두고 있다TTafesse \& Wien 2018). 행동적 또는 물리적 참여는 실제 행동의 확장된 의도이다(Macey \& Schneider, 2008). 소비자는 거래를 넘어서 특정 브랜드와 기업에 대해 능동적으로 노력할 때 브랜드와 기업에 관여된다Nan Doom, Lemon, Mittal, Nass, Pick, Pimer, \& Verhoef, 2010). 그러므로 행동적 참여는 소비자가 특정 브랜드 또는 기업에 지식, 경험, 시간, 관계, 사회적 영향력 등의 자원을 투여하는 자발적인 행동이다(Van Doom et al, 2010). 행동적 참여는 소비자에 의해 실행되며 기업의 마케팅 기능에 다른 외부의 자원이 추가되는 것을 의미한다(Hameling, Moffett, Amold, \& 
Carlson, 2016). 소비자의 행동적 참여는 특정한 자극에 반응하는 행동 의도이다. 따라서 본 연구는 브랜드와의 상호작용을 위해 소비자가 투여한 열정, 노력, 시간의 수준으로 행동적 참여를 정의하였다. 소비자가 높은 수준의 행동적 참여를 지각할 때 브랜드를 사용할 가능성이 높아지므로 소비자의 행동적 참여의 결과는 구매의도라고 할 수 있다(Ahn \& Bad, 2018). 본 연구는 행동적 참여가 브랜드에 대한 소비자 행동을 실질적으로 반영하는 개념으로 보고SNS 활동과 긍정적 구전의 결과로서 행동적 참여의 중요성을 연구하고자 하였다.

\section{3. 연구설계}

\section{1. 연구가설}

\subsection{SNS 정보품질 특성과 SNS 참여 간의 관계}

온라인 브랜드 커뮤니티에서 브랜드와 관련된 정보품질은 소비자의 참여에 영향을 주고(Dessart et al, 2015; Dholakia et al, 2009), 높은 정보품질은 소비자에게 긍정적인 브랜드 경험을 제공하며 궁극적으로 참여의도와 지속적 관계를 강화한다(Dessart et al, 2015).

또한 풍부한 정보를 제공하는 온라인 브랜드 커뮤니티는 외부에 매력적으로 보이므로 신규 회원을 가입시키는 것이 용이하다(Gorla, Somers, \& Wong, 2010). 소비자가 지각하는 온라인 정보의 혜택은 만족, 긍정적 태도와 구매의도와 관계가 있으므로 외식업체의 상품 정보에 대한 지각된 혜택은 긍정적 구전의도에 영향을 미친다(Kim, Choi, \& Shin, 2019).

정보의 품질은 커뮤니티 몰입(lang, Olfman, Ko, Koh, \& Kim, 2008) 소비자 만족 (Ghasemaghaei \& Hassanein, 2015), 브랜드 인지도 (Barreda, Bilgihan, Nusair, \& Okumus, 2015) 및 조직 효율성(Gorla et al, 2010) 측면에서 기업과 브랜드의 SNS 에 영향을 줄 가능성이 높다. 따라서 최근의 믿을 수 있는 정보를 소비자에게 제공하는 브랜드 커뮤니티는 확실한 경쟁 우위를 가지게 될 것이다(Jang et al, 2008). 신뢰할 만한 정보원천으로부터 제공되는 관련성이 높고, 충분하며, 자세하면서, 가치 있는 정보는 소비자로 하여금 브랜드를 잘 알게 하고 브랜드와 관련한 긍정적 의사결정을 하도록 도와준다(Watts \& Zhang, 2008; Zheng, Zhao, \& Stylianou, 2013).

위의 연구 결과들은 공통적으로 SNS 정보품질이 높을수록 SNS 사용자들의 참여가 증가할 수 있다는 점을 알려준다. 따라서 본 연구에서는 SNS 의 정보품질이 SNS 사용자의 참여에 미치는 영향을 분석하고자 다음과 같은 가설을 수립하였다.

H1: SNS 정보품질 특성은 SNS 참여에 영향을 미칠 것이다.

H1-1: SNS 정보품질 특성은 SNS 활동에 정(+)의 영향을 미칠 것이다.

H1-2: SNS 정보품질 특성은 긍정적 구전에 정(+)의 영향을 미칠 것이다.

\subsubsection{SNS 쾌락적 특성과 SNS 참여 간의 관계}

소비자가SNS 에서 얻은 쾌락적 즐거움은 SNS 에 대한 긍정적 태도에 영향을 미친다(Koohikamali \& Sidorova, 2017). 비슷한 개념인 여흥은 주요한 SNS 이용동기로 브랜드 SNS 에 참여하는 요인 중 하나이다de Vies et al, 2012; Rohm et al, 2013).

페이스북에서 브랜드 콘텐츠의 생생함과 즐거움은 좋아요, 공유, 댓글 등 소비자의 SNS 활동에 영향을 미친다(Nguyen \& Bang, 2019). 소비자가 온라인 정보가 재미있다고 인식하면 소셜 미디어를 이용하고 정보를 공유하는데 더 많은 시간을 사용한다(Km et al, 2017). 그러므로 SNS 에서 경험하는 쾌락적 특성은 소비자의 SNS 참여 수준을 결정하는 중요한 요인이 될 수 있을 것이다.

본 연구에서는 이러한 연구 결과를 바탕으로 SNS 사용자의 쾌락적 특성에 대한 평가가 SNS 참여 수준에 미치는 영향을 분석하고자 다음과 같은 가설을 수립하였다.

H2: SNS 쾌락적 특성은 SNS 참여에 영향을 미칠 것이다.

H2-1: SNS 쾌락적 특성은 SNS 활동에 정(+)의 영향을 미칠 것이다.

H2-2: SNS 쾌락적 특성은 긍정적 구전에 정(+)의 영향을 미칠 것이다.

\subsubsection{SNS 관계 특성과 SNS 참여 간의 관계}

SNS 회원 간의 사회적 상호작용이 많을 수록 정보교환의 강도와 빈도가 커진다(Larson, 1992; Ring \& Van de ven, 1994). SNS 에서 사회적 상호작용 관계는 다른 회원과 친근한 정도와 커뮤니케이션 빈도에 관련되어 있다(Wang \& Chen, 2012). 또한 온라인 커뮤니티에서 사회적 상호작용 관계는 회원 간의 신뢰와 관계 몰입, 공유된 가치, SNS 지속 사용의도에 긍정적 영향을 준다(Lin \& Lu, 2011; Wang \& Chen, 2012).

또한 블로그 특성 중 상호작용성이 구전의도에 미치는 영향이 큰 것으로 나타나 양방향 커뮤니케이션을 가능하게 하는 가치요소 제공이 중요하다(Shin \& Kim, 2017). 위의 연구 결과들은 공통적으로 SNS 관계 특성이 높을수록 SNS 사용자들의 참여가 증가할 수 있다는 점을 알려준다. 따라서 본 연구에서는 SNS 의 관계 특성이 SNS 사용자의 참여에 미치는 영향을 분석하고자 다음과 같은 가설을 수립하였다.

H3: SNS 관계 특성은 SNS 참여에 영향을 미칠 것이다.

H3-1: SNS 관계 특성은 활동에 정(+)의 영향을 미칠 것이다.

H3-2: SNS 관계 특성은 긍정적 구전에 정(+)의 영향을 미칠 것이다.

\subsubsection{SNS 활동과 긍정적 구전 간의 관계}

커뮤니티 회원은 커뮤니티에 대한 관여와 활동이 많아질수록 커뮤니티 유지와 추천의도가 강해지며, 적극적으로 상품과 브랜드에 대해 긍정적으로 말한다(Algesheimer et al, 2005). 또한 게시판이나 상품 
리뷰 페이지에서 소비자 활동과 다른 소비자의 활동에 대한 반응은 구전 품질에 긍정적인 영향을 미친다(Km \& Song, 2010).

한편 온라인 활동은 소비자에게 공통의 관심사인 경험과 상품정보를 공유할 수 있게 하고 지식의 공유, 아이디어 전파, 커뮤니티 회원 간의 감정적 교류를 촉진한다(Koh \& Km, 2004). 온라인 활동은 소비자가 의견과 경험을 공유하는 것을 촉진하기 때문에, 소비자는 더 많은 대화에 참여하게 되고 다른 소비자로부터 많은 정보를 얻을 수 있다(Dholakia, Bagozi, \& Pearo, 2004).

이와 같이 소비자의 활동을 통해 생산된 정보는 소비자 사이에 반복적으로 공유되면서 상호작용의 기회를 제공한다(Pai \& Tsai, 2011). 그러므로 온라인 활동을 통해 소비자 사이에 반복되는 긍정적 상호작용을 긍정적 구전으로 볼 수 있다(Yang, Li, Km, \& Km, 2015). 또한 커뮤니티 활동은 추천행동과 커뮤니티 회원 유지, 커뮤니티 후원자 브랜드 이미지에 긍정적 영향을 미친다(Woisetschläger et al, 2008). 한편 소비자의 활동과 몰입은 부정적 구전 보다 긍정적 구전의 전달을 촉진한다(Flle \& Prince 1992; Moore, Moore, \& Capella, 2005; Richins \& Shaffer, 1987; Stokes, 1997).

위의 연구 결과들은 소비자의 브랜드 SNS 활동이 높을수록 긍정적 구전이 증가할 수 있다는 점을 알려 준다. 따라서 본 연구에서는 SNS 활동이 긍정적 구전에 미치는 영향을 분석하고자 다음과 같은 가설을 수립하였다.

H4: SNS 활동은 긍정적 구전에 정(+)의 영향을 미칠 것이다.

\subsubsection{SNS 활동과 행동적 참여 간의 관계}

소비자의 관여도가 소비자 브랜드 참여의 구성 요소인 인지적 과정, 감정 그리고 활성화에 유의한 영향을 준다(Hollebeek et al, 2014). 소비자의 소셜 미디어 활동은 관여도와 비슷한 개념으로 소비자 브랜드 참여에 긍정적 영향을 준다(Dijkmans, Kerkhof \& Beukeboom, 2015). 또한 온라인 브랜드 커뮤니티에 몰입하는 소비자는 브랜드에 몰입한다(Km, Bae, \& Kang, 2008). 온라인 브랜드 커뮤니티 참여는 전반적으로 브랜드 참여를 증대 시키므로 커뮤니티 참여는 브랜드 참여와 긍정적 관계가 있다(Wirt, den Ambtman, Bloemer, Horváth, Ramaseshan, van de Kundert, Gurhan Canli, \& Kandampully, 2013).

한편 Schau, Muñiz, and Amould(2009)는 커뮤니티 활동이 브랜드 참여에 긍정적인 영향을 미친다고 하였다. 소비자는 기업과 공동으로 상품과 관련된 활동을 할 때 그들의 아이디어와 제안을 서비스 기업과 공유하는 경향이 있다(Chen, Tsou, \& Ching, 2011). 소비자의 브랜드에 대한 개인적 자원의 투여는 브랜드에 대한 만족을 높일 수 있다Cermak, Flle, \& Prince, 1994).

자발적인 소비자 활동은 기업이 더 좋은 서비스 품질을 제공하도록 소비자가 지원하는 의도적인 행동이다(Bettencourt, 1997; Esingerich, Auh,
\& Merlo, 2014). 소비자 활동은 자발적인 행동적 성과로 소비자가 기업에게 건설적인 피드백과 제안을 제공하는 정도로 정의된다(Eisingerich et al, 2014).

소비자 활동은 적시에 시장 정보에 접근하고(Fang, 2008), 오퍼링을 개선하고(Fomell \& Wemerfelt, 1987), 새로운 서비스 개발을 지원하는(Von Hippel, 2009) 혜택을 기업에 제공한다. 소비자가 브랜드 콘텐츠와 상호작용이 많아지면, 소비자의 브랜드 태도와 브랜드 연상구조에도 영향을 미친다(Keller, 2003). 그러므로 기업과 소비자 양측에 이익이 되는 소비자 활동은 기업과 브랜드에 대한 소비자의 열정을 유도하고 결과적으로 기업과 브랜드에 대한 행동적 참여를 증가시킨다(Bagozi \& Dholakia, 2006b; Vivek, Beatty, \& Morgan, 2012).

이러한 선행연구를 기반으로 SNS 사용자들의 참여 활동이 증가할수록 브랜드에 대한 행동적 참여가 증가한다고 가정할 수 있다. 본 연구에서는 SNS 활동과 행동적 참여 간의 관계를 분석하고자 다음과 같은 가설을 수립하였다.

H5: SNS 활동은 행동적 참여에 정(+)의 영향을 미칠 것이다.

\subsection{6. 긍정적 구전과 행동적 참여 간의 관계}

긍정적 구전은 전형적으로 구매 등 긍정적인 브랜드 태도에 영향을 미치는 반면 부정적 구전은 구매의도를 감소시키고 브랜드 관련 행동을 방해한다(Bansal \& Voyer, 2000; Ryu \& Feick, 2007). 구전이 브랜드 참여에 미치는 영향은 정서적, 인지적, 행동적 반응으로 분류할 수 있다.

구전에 의한 정서적 반응은 열정, 확신, 낙관(Phelps, Lewis, Mobilio, Peny, \& Raman, 2004; Sweeney, Soutar, \& Mazzarol, 2008) 등의 구전 수용자의 고조된 감정적 상태를 의미한대(Chistophe \& Rime, 1997). 인지적 반응은 높은 브랜드 인지도(Ferguson, 2008; Lu, 2006; Sheth, 1971), 상품에 대한 높은 기대(Webster, 1991; Zeithaml et al, 1993) 그리고 브랜드 기억 인출 및 브랜드 고려를 의미한다(Grewal, Cine, \& Davies 2003). 행동적 반응은 상품 사용 시도와(Anderson \& Golden, 1984; Katz \& Lazarsfeld, 1955; Manchanda, Ying, \& Youn, 2008; Sheth, 1971; Sultan, Farley, \& Lehmann, 1990; Trusov, Bucklin, \& Pauwels, 2009) 고객 간의 정보 전달을 통해 발생하는 브랜드 전환(Katz \& Lazarsfeld, 1955; Wangenheim \& Bayón, 2004; Wangenheim \& Bayon, 2007)을 의미한다.

구전은 판매뿐만 아니라 소비자가 서비스 제공자와 장기적 관계를 지속하고자 하는 충성도에도 영향을 미친다Reinart \& Kumar, 2000; Reinart \& Kumar, 2002; Yu \& Dean, 2001). 구전을 통해 획득한 소비자는 더 오래 유지되고 다른 경로를 통해 확보한 소비자 보다 가치가 있다(Schmitt, Skiera, \& Van den Bulte, 2011).

위의 연구 결과들은 긍정적 구전이 긍정적 브랜드 태도와 브랜드 관련 결과에 영향을 미친다는 것을 지지하며, 긍정적 구전이 많아질수록 
행동적 참여가 높아진다는 점을 알려준다. 따라서 본 연구에서는 긍정적 구전이 행동적 참여에 미치는 영향을 분석하고자 다음과 같은 가설을 수립하였다.

H6: 긍정적 구전은 행동적 참여에 정(+)의 영향을 미칠 것이다.

\section{4. 실증분석}

\section{1. 표본설계 및 분석방법}

\subsection{1. 표본설계}

본 연구의 가설을 검증하기 위해 선행연구를 기반으로 설문지를 작성하였고 외식 브랜드 SNS 이용 경험이 있는 소비자중에 외식 프랜차이즈 이용 경험이 있는 이용자를 무작위 추출하여 자료를 수집하였다. 설문조사는 2020 년 2 월 6 일부터 2020 년 2 월 11 일까지 약 6 일간 시행되었으며 최종 433 명의 응답 내용이 유효한 것으로 밝혀져 최종 실증 분석에 이용되었다.

\subsection{2. 변수의 측정 및 정의}

본 연구의 가설을 검증하기 위한 항목은 모두 5 점 척도(1 점: 전혀 그렇지 않다, 5 점: 매우 그렇다)로 측정되었다.

SNS 의 정보품질 특성은 SNS 가 제공하는 정보의 정확성, 신뢰성, 적시성, 관련성, 완전성의 정도로 정의되었고 Zhou and Lu(2010), Chavez, Yu, Gimenez, Fynes, and Wiengarten(2015), Koohikamali and Sidorova(2017)의 연구에서 사용한 설문 항목들을 본 연구에 맞게 수정하여 5 개의 항목으로 측정되었다.

외식업체의 SNS 쾌락적 특성은 외식업체 SNS 의 이용자가 경험하는 즐거움, 기쁨, 흥미, 재미의 정도로 정의되었고 Koohikamali and Sidorova(2017), Van der Hejden (2004)의 연구에서 사용된 문항을 수정하여 4 개 항목으로 측정되었다. SNS 관계 특성은 외식업체 SNS 이용자 간의 관계의 강도와 빈도로 정의되었고 Yang, Lu, and Wei(2016), Zhang, Li, Wu, and L(2017)의 연구를 본 연구에 맞게 수정하여 4 개의 항목으로 측정하였다.

SNS 참여는 SNS 활동, 긍정적 구전으로 구분하였다. SNS 활동은 외식업체 SNS 이용자가 대화, 협력, 공유 등을 통해 SNS 에 참여하는 정도로 정의되었고 Zheng et al.(2015), Men and Tsai(2015)의 연구에서 사용된 문항을 수정하여 5 개 항목으로 측정되었다.

긍정적 구전은 외식업체 SNS 이용자가 다른 사람들에게 이 SNS 를 추천하고 가입을 권유하며 혜택을 소개하는 정도로 정의되었고 Zheng et al. (2015), Hsu, Wang, and Chih(2018), Chen and Hung(2010)의 연구를 본 연구에 맞게 수정하여 4 개 항목으로 측정되었다.

행동적 참여는 브랜드와의 상호작용을 위해 소비자가 투여한 열정, 노력, 시간의 수준으로 정의되었고 Gutiérez, Gllán, and Zquierdo(2004), Lee, Jeong, and Yoo(2008)의 연구에서 사용된 문항을 수정하여 3 개의 문항으로 측정되었다.

\section{2. 표본의 일반적 특성}

본 연구에서 이용된 433 명의 응답자에 대한 일반적 특성은 Table: 1 과 같다. 성별은 남자가 $50.1 \%(217$ 명)로 여자(49.9\%)에 비해 약간 많은 것으로 나타났다.

Table 1: Demographic Profile of the Respondents $(n=433)$

\begin{tabular}{|c|c|c|c|}
\hline & & $\mathbf{n}$ & $\%$ \\
\hline \multirow{2}{*}{ Gender } & Male & 217 & 50.1 \\
\hline & Female & 216 & 49.9 \\
\hline \multirow{4}{*}{$\begin{array}{l}\text { Educational } \\
\text { Level }\end{array}$} & Below high school & 120 & 27.7 \\
\hline & Undergraduate & 59 & 13.6 \\
\hline & Four year university & 224 & 51.7 \\
\hline & Graduate school & 30 & 6.9 \\
\hline \multirow{5}{*}{$\begin{array}{l}\text { Monthly } \\
\text { income }\end{array}$} & Less than 2 million won & 186 & 43.0 \\
\hline & $\begin{array}{l}2 \text { million - Less than } \\
3 \text { million won }\end{array}$ & 84 & 19.4 \\
\hline & $\begin{array}{c}3 \text { million - Less than } \\
4 \text { million won }\end{array}$ & 98 & 22.6 \\
\hline & $\begin{array}{l}5 \text { million - Less than } \\
6 \text { million won }\end{array}$ & 44 & 10.2 \\
\hline & More than 7 million won & 21 & 4.8 \\
\hline \multirow{2}{*}{$\begin{array}{l}\text { Marital } \\
\text { status }\end{array}$} & Single & 292 & 67.4 \\
\hline & Married & 141 & 32.6 \\
\hline \multirow{8}{*}{ Job } & Officer & 179 & 41.3 \\
\hline & Owner & 17 & 3.9 \\
\hline & Public Official & 11 & 2.5 \\
\hline & Professional & 17 & 3.9 \\
\hline & Student & 151 & 34.9 \\
\hline & Housewife & 22 & 5.1 \\
\hline & Engineer & 8 & 1.8 \\
\hline & Others & 28 & 6.4 \\
\hline \multirow{4}{*}{ Age } & $10-19$ & 84 & 19.4 \\
\hline & $20-29$ & 127 & 29.3 \\
\hline & $30-39$ & 132 & 30.5 \\
\hline & $40-49$ & 90 & 20.8 \\
\hline
\end{tabular}


결혼 유무는 미혼이 $67.4 \%(292$ 명)로 기혼(32.6\%)에 비해 많은 것으로 나타났다. 학력은 대학교 졸업이 $517 \%(224$ 명)로 가장 많은 것으로 나타났으며, 다음으로 고등학교 졸업 이하(27.7\%), 대학교 재학(13.6\%), 그리고 대학원 졸업(69\%)의 순으로 나타났다.

직업은 사무직이 $413 \%(179$ 명)로 가장 많은 것으로 나타났으며, 다음으로 학생 $34.9 \%)$, 기타 $6.4 \%)$, 주부(5.1\%), 자영업 (3.9\%)순으로 나타났다. 연령은 30 대가 $30.5 \%(132$ 명)로 가장 많은 것으로 나타났으며, 20 대 (293\%), 40 대(20.8\%), 그리고 10 대(19.4\%)의 순으로 나타났다.

\section{3. 측정항목의 타당성 및 신뢰성 검증}

\subsection{1 확인적 요인분석}

본 연구는 SmartPLS 32.9를 활용하여 이용된 연구단위에 대한 확인적 요인 분석을 통해 타당성과 신뢰도를 검증하였다. 확인적 요인 분석 결과는 다음과 같다. 집중 타당성 분석결과 각 연구단위의 요인 적재량은 0.60 0.95 의 범위에 있어 모두 0.5 이상으로 나타났고, AVE 값은 SNS 정보품질 특성이 0.568 , SNS 쾌락적 특성이 0.686, SNS 관계특성이 $0.889, \mathrm{SNS}$ 활동이 0.653 , 긍정적 구전이 0.714 , 행동적 참여가 0.761 로 0.5 보다 높게 나타나 집중 타당성은 검증되었다.

신뢰성 분석에서는 Cronbach's $\alpha$ 값이 SNS 정보품질 특성이 0.829 , SNS 쾌락적 특성이 0.847 , SNS 관계 특성이 0.958 , SNS 활동이 0.867 , 긍정적 구전이 0.866 , 행동적 참여가 0.843 으로 일반적 기준인 0.7 보다 높게 나타났고 CR값은 SNS 정보품질 특성이 0.866 , SNS 쾌락적 특성이 0.897 , SNS 관계 특성이 0.970, SNS 활동이 0.904, 긍정적 구전이 0.909, 행동적 참여가 0.905 로 일반적 기준인 0.7 보다 높게 나타나 설문항목의 신뢰도는 높은 것으로 나타났다(Appendix 1 Refer).

또한 판별 타당성은 Fomell-Larcker 기준(Fomell \& Larcker, 1981)에 의해 모든 AVE 값의 제곱근 값이 상관계수 값보다 크고, 상관계수의 값의 이질성-단질성 특성 비율을 나타내는 Heterotrait-Monotrait Ratio (HTMT) 값이 0.164 0.812의 범위에 있어 모든 HTMT 값이 0.9 보다 작은 것으로 나타나 판별 타당성은 검증되었다(Henseler, Ringle, \& Sarstedt, 2015)(Appendix 2,3 Refer).

\subsection{2 연구모형 평가}

SmartPLS 32.9 를 이용한 연구모형의 평가 결과는 다음과 같다. 첫째, VFFariance Inflation Factor)를 이용하여 다중 공선성을 측정하였다. VF 값은 1497 6484 로 나타나 일반적인 기준인 10 보다 낮아 공통방법편의의 문제는 없는 것으로 검증되었다(Hair, Hult, Ringle, \& Sarstedt, 2017).

둘째, 내생변수의 설명력을 나타내는 결정계수인 $R^{2}$ 값은 SNS 활동이 0.502 , 긍정적 구전이 0.546, 행동적 참여가 0.161 로 나타나 Falk and Miller
(1992)가 제시한 0.10 보다높아서 내생변수의 설명력은 충분한 것으로 나타났다. Chin(1998)은 설명력의 기준을 0.67(강), 0.33(중), 0.19(약)으로 제시하였고, 이 기준에 의하여 본 연구의 내생변수인 SNS 활동과 긍정적 구전의 설명력은 중간 수준이고 행동적 참여의 설명력은 약한 것으로 판단된다.

셋째, 내생변수의 중복성을 표시하는 연구단위 교차타당성 중복성(Construct cross-validated redundancy, $Q^{2}$ ) 값이 0 보다 클 때 예측 적합도가 있는 것으로 평가하는데 본 연구에서는 SNS 활동이 0322, 긍정적 구전이 0.380 , 행동적 참여가 0.119 로 나타나 모형의 예측력은 충분한 것으로 검증되었다. 넷째 연구모형의 예측력을 설명하는 SRMR(Standardized root mean square residual) 값은 0.074 로 나타나 기준인 0.1 또는 0.08 보다 작게 나타나 모형의 예측력은 유의한 것으로 밝혀졌다(Appendix 4 Refer).

\section{4. 연구가설의 검정}

\subsection{1. 연구가설의 검증 결과}

SNS 정보품질 특성, SNS 쾌락적 특성, SNS 관계 특성이 SNS 활동, 긍정적 구전, 행동적 참여에 미치는 구조적 관계를 분석한 결과는 다음과 같다.

$\mathrm{H} 1$ 은 SNS 정보품질 특성과 SNS 참여 간의 관계를 알아보기 위한 것이다. 우선 SNS 정보품질 특성이 SNS 활동에 정(+)의 영향을 미칠 것이라는 H1-1 을 검증한 결과 $(\beta=0.100, \mathrm{t}-\mathrm{value}=2.184, \mathrm{p}<0.05)$ 로 SNS 정보품질 특성은 SNS 활동에 정(+)의 영향을 미치는 것으로 나타났다. 따라서 H1-1 은 채택되었다. 다음으로 SNS 정보품질 특성이 긍정적 구전에 정(+)의 영향을 미칠 것이라는 $\mathrm{H} 1-2$ 를 검증한 결과 $(\beta=0.035, \mathrm{t}-$ value $=0.763$, n. s.)로 SNS 정보품질 특성은 긍정적 구전에 정(+)의 영향을 미치지 않는 것으로 나타났다. 따라서 H1-2는 기각되었다.

$\mathrm{H} 2$ 는 SNS 의 쾌락적 특성과 SNS 참여 간의 관계를 알아보기 위한 것이다. 우선 SNS 의 쾌락적 특성이 SNS 활동에 정(+)의 영향을 미칠 것이라는 H2-1을 검증한 결과 ( $\beta=0.170, t-v a l u e=3.541, p<0.001)$ 로 SNS의 쾌락적 특성은 SNS 활동에 정(+)의 영향을 미치는 것으로 나타났다. 따라서 H2-1 은 채택되었다. 다음은 SNS 의 쾌락적 특성이 긍정적 구전에 정(+)의 영향을 미칠 것이라는 $\mathrm{H} 2-2$ 를 검증한 결과 $(\beta=0.150, \mathrm{t}-$ value $=2.962, \mathrm{p}<0.01)$ 로 SNS 의 쾌락적 특성은 긍정적 구전에 정(+)의 영향을 미치는 것으로 나타났다. 따라서 H2-2는 채택되었다.

$\mathrm{H} 3$ 은 SNS 의 관계 특성과 SNS 참여 간의 관계를 알아보기 위한 것이다. 우선 SNS 의 관계 특성이 SNS 활동에 정(+)의 영향을 미칠 것이라는 H3-1 을 검증한 결과 ( $\beta=0.628, t-v a l u e=21648, p<0.001)$ 로 SNS 의 관계 특성은 SNS 활동에 정(+)의 영향을 미치는 것으로 나타났다. 따라서 H3-1 은 채택되었다. 다음으로 SNS 의 관계 특성이 긍정적 
구전에 정(+)의 영향을 미칠 것이라는 H3-2 를 검증한 결과 $(\beta=0.183, \mathrm{t}-$ value $=3.548, p<0.001)$ 로 SNS 의 관계 특성이 긍정적 구전에 미치는 정(+)의 영향은 유의한 것으로 나타났다. 따라서 $\mathrm{H3}-2$ 는 채택되었다.

$\mathrm{HA}$ 는 SNS 활동과 긍정적 구전과의 관계를 알아보기 위한 것이다. SNS 활동이 구전에 정(+)의 영향을 미칠 것이라는 $\mathrm{H} 4$ 를 검증한 결과 $(\beta=0.526, \mathrm{t}-\mathrm{value}=9.899, \mathrm{p}<0.001)$ 로 SNS 활동은 긍정적 구전에 정( + )의 영향을 미친다는 사실이 밝혀졌다. 따라서 $\mathrm{H} 4$ 는 채택되었다.

$\mathrm{H} 5$ 는 SNS 활동과 행동적 참여와의 관계를 알아보기 위한 것이다. $\mathrm{SNS}$ 활동이 행동적 참여에 정(+)의 영향을 미칠 것이라는 $\mathrm{H} 5$ 를 검증한 결과 ( $\beta=0.185, \mathrm{t}$-value $=2.737, \mathrm{p}<0.01)$ 로 SNS 활동이 행동적 참여에 미치는 긍정적인 영향은 유의한 것으로 나타났다. 따라서 $\mathrm{H} 5$ 는 채택되었다.

$\mathrm{H6}$ 은 긍정적 구전과 행동적 참여와의 관계를 알아보기 위한 것이다. 긍정적 구전이 행동적 참여에 정(+)의 영향을 미칠 것이라는 $\mathrm{H6}$ 을 검증한 결과 $(\beta=0249, t-v a l u e=3.532, p<0.001)$ 로 긍정적 구전이 행동적 참여에 미치는 정(+)의 영향은 통계적으로 유의한 것으로 나타났다. 따라서 $\mathrm{H} 6$ 은 채택되었다(Appendix 4 Refer).

\subsection{2. 효과크기 $\left(f^{2}\right)$ 의 분석}

효과크기(effect size, $\left.f^{2}\right)$ 는 독립변수의 종속변수에 대한 상대적 효과를 분석하기 위해 활용되는데(Chin, 1998), 0.35(대), 0.15(중), 0.02(소)의 기준으로 분류된다(Cohen, 1988). 독립변수인 SNS 정보품질 특성(0.012)은 종속변수인 SNS 활동에 효과 크기가 거의 없는 것으로 나타났고, SNS 쾌락적 특성(0.033)은 SNS 활동에 효과크기가 약한 반면, SNS 관계 특성(0.746)은 효과크기가 강하게 나타났다. 또한 독립변수인 SNS 정보품질 특성(0.002)은 종속변수인 긍정적 구전에 효과 크기가 거의 없는 것으로 나타났고, SNS 쾌락적 특성(0.027)과 SNS 관계 특성(0.040)은 긍정적 구전에 효과크기가 약하게 나타났다. SNS 활동(0304)은 긍정적 구전에 대해 중간 정도의 효과크기가 나타났으며, 행동적 참여에 대한 SNS 활동(0.020), 긍정적 구전(0.037)의 효과크기는 약하게 나타났다(Appendix 4 Refer).

\subsection{3 매개효과 분석}

Bootstrapping 을 이용한 매개역할 분석을 실행한 결과 SNS 정보품질 특성 $\rightarrow$ 긍정적 구전의 관계에서 SNS 활동은 완전매개 역할을 하는 것으로 나타났고(직접효과가 유의하지 않고 간접효과만 유의한 것으로 나타날 경우), SNS 쾌락적 특성, SNS 관계 특성과 긍정적 구전의 관계에서 SNS 활동은 부분매개 역할을 하는 것으로 나타났다(직접효과와 간접효과가 모두 유의할 경우). 또한 SNS 참여와 행동적 참여의 관계에서 긍정적 구전은 부분매개 역할을 하는 것으로 밝혀졌다(Appendix 5 Refer).

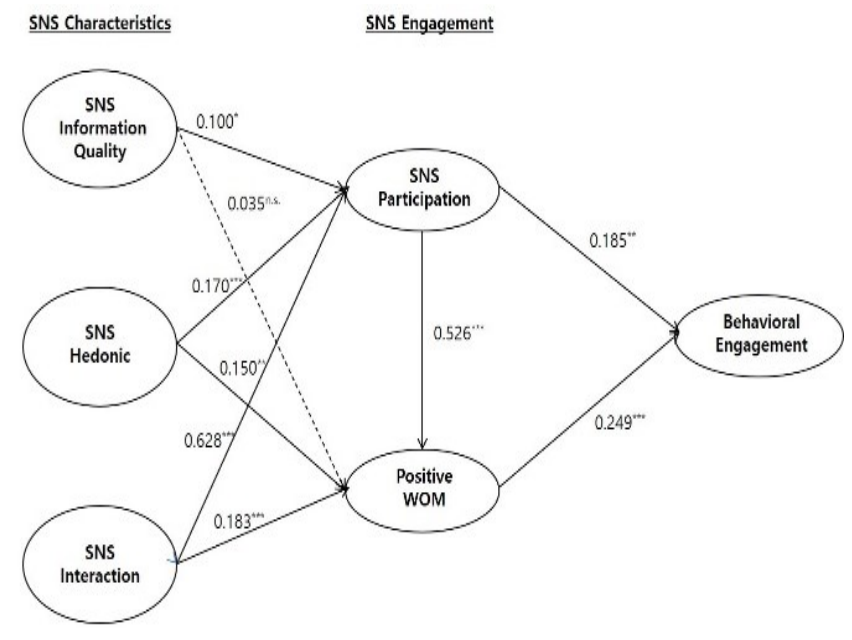

Figure 1: Estimates of the Structural Model

\section{5. 결론}

\section{1. 연구결과의 요약 및 시사점}

본 연구는 외식업체 SNS 특성이 소비자의 SNS 참여에 미치는 영향을 검증하고, SNS 참여가 SNS 프로모션의 성과로서 소비자 브랜드 참여에 어떤 영향을 미치는지를 실증적으로 분석하였다. 이를 위하여 SNS 특성을 정보품질 특성, 쾌락적 특성, 관계 특성으로 구분하여 SNS 참여에 미치는 영향을 조사하였고 SNS 참여와 소비자의 행동적 참여 간의 구조적 관계를 분석하여 외식업체의 SNS 마케팅 전략 수립에 기초가 되는 이론적, 실무적 시사점을 제시하였다.

본 연구의 이론적 시사점은 다음과 같다. 첫째, 정보시스템 성공 모델은 정보 시스템의 속성을 정보품질과 시스템 품질로 구분하여 시스템 이용과 만족, 성과에 미치는 영향을 연구하였으나(DeLone \& McLean, 1992), 본 연구는 SNS 특성의 연구목적을 시스템 이용 측면에 한정하지 않고 소비자 행동에 미치는 효과 검증에 두고 정보품질과 쾌락적 수준, 관계 등 소비자 측면의 SNS 특성을 종합적으로 분석하여 SNS 프로모션의 직접적 효과로 측정되는 소비자의 SNS 참여에 미치는 영향을 조사함으로써 기존 연구와의 차별성을 확보하였다.

둘째, 기존 연구에서는 SNS 참여를 SNS 활동과 긍정적 구전으로 구성된 개념으로 정의하고 태도에 미치는 영향을 중심으로 연구하였으나(Algesheimer et al, 2005; Zheng et al, 2015), 본 연구에서는 SNS 참여 개념을 구성하는 SNS 활동과 긍정적 구전 간의 관계를 규명함으로써 SNS참여의 구성요소 간의 구조적 관계를 명확히 하였다. 
셋째, 본 연구는 가상의 커뮤니티 특성을 가진 SNS 에서의 소비자 참여가 브랜드에 대한 행동적 참여에 미치는 영향을 분석하여 브랜드 관리 전략의 요소로서 SNS 참여에 대한 연구 범위를 확장하였다.

실증 분석 결과를 요약하면 아래와 같다. 첫째, SNS 특성의 하위요인인 SNS 의 정보품질 특성은 SNS 활동에 긍정적 영향을 미치지만 긍정적 구전에는 영향을 미치지 않는 것으로 나타났다.

최근 외식업체가 제공하는 SNS 정보품질의 수준이 평준화되어 정보품질만으로 긍정적 구전 활동에 충분하지 않다고 판단할 수 있다. 그러나 SNS 정보품질 특성과 긍정적 구전과의 관계에서 SNS 활동이 완전 매개 역할을 하는 것으로 나타났다. 이는 전반적으로 브랜드 커뮤니티 관련한 연구에서 정보품질과 가상의 상호작용이 소비자 참여에 영향을 미친다는Islam and Rahman (2017)의 연구와 일치한다.

한편 SNS 쾌락적 특성은 SNS 활동과 긍정적 구전에 영향을 주는 것으로 나타났다. 이는 SNS 이용에서 얻은 쾌락적 즐거움의 정도에 따라 SNS 참여에 긍정적인 태도를 갖게 된다고 주장한 Koohikamali and Sidorova(2017)의 연구와 일치하는 결과를 보여주었다. 또한 SNS 관계 특성은 SNS 활동과 긍정적 구전에 유의한 영향을 미치는 것으로 나타나 SNS 회원 간의 상호작용 관계가 신뢰와 관계 몰입, 공유된 가치, SNS 지속 이용의도에 긍정적인 영향을 준다는 Lin and Lu (2011), Wang and Chen(2012)의 연구 결과를 지지하는 것으로 나타났다.

둘째, SNS 활동은 긍정적 구전에 긍정적 영향을 미치는 것으로 나타났다. 이는 소비자의 커뮤니티에 대한 관여와 활동이 커뮤니티 추천의도에 긍정적인 영향을 미친다는 Algesheimer et al. (2005)의 연구와 온라인 게시판이나 상품 리뷰페이지에서 소비자의 활동은 구전품질과 관계가 있다는(Kim\& Song, 2010)의 연구와 일치한다.

셋째, SNS 활동은 행동적 참여에 긍정적 영향을 미치는 것으로 나타났다. 이는 소비자 활동은 소비자가 브랜드와 기업에 대해 행동으로 표현하는 자발적 성과의 주요한 형태라는 Eisingenich et al.(2014)의 주장과 일치한다. 또한 소비자 활동은 더 높은 수준의 열정을 일으켜 결과적으로 기업과 브랜드에 대한 행동적 참여를 증가시킨다는 Bagozi and Dholakia (2006)b; Vivek et al. (2012)의 연구를 지지한다.

넷째, 긍정적 구전은 행동적 참여에 긍정적 영향을 미치는 것으로 나타났으며, 이는 소비자의 소셜 미디어 참여는 관여도 수준과 비슷한 개념으로 소비자 브랜드 참여에 긍정적 영향을 미친다는 Dijkmans et al. (2015)의 연구를 지지한다. 또한 구전은 상품 사용 시도, 브랜드 전환 등을 의미하는 행동적 반응을 통해 브랜드 참여에 영향을 미친다는 Lang and Hyde(2013)의 연구와 일치한다.

이러한 실증 분석 결과를 토대로 하는 실무적 시사점은 다음과 같다. 첫째, 외식업체는 SNS 정보의 정확성, 신뢰성, 적시성, 관련성, 완전성 측면에서 제공하는 정보품질의 경쟁력을 높이고 소비자가 SNS 이용 시 재미와 즐거움을 느낄 수 있도록 콘텐츠를 관리해야 한다.
또한 회원 간의 빈번한 교류가 발생할 수 있도록 기회를 제공하여 소비자들의 SNS 참여가 증가하도록 관리해야 한다. 또한 SNS 이용자들이 원하는 수준의 쾌락적 콘텐츠가 제공되지 못한다면 사용자들의 SNS 참여 활동은 위축될 수밖에 없다는 사실이 밝혀졌다. 특히 긍정적 구전의 활성화를 위해서는 SNS 정보품질보다는 쾌락적 수준을 제고하는 전략이 더 중요하다는 점을 시사해준다.

SNS 는 원래의 목적이 커뮤니티 형성과 상호작용이라는 점에서 SNS 회원이 상호작용하고 브랜드를 공동으로 창조하는 SNS 의 관계적 프로모션의 중요성을 다시 한번 확인할 수 있었다. 이를 위해 최근에 많이 시도되는 동영상을 이용한 실시간 정보 전달과 소비자가 선호하는 정보 제공 방식을 효과적으로 활용하고 소비자 간의 교류 활성화를 위한 커뮤니티 지원을 강화할 필요가 있다.

둘째, SNS 에서 적극적으로 게시글을 업로드하고, 다른 소비자와 공유하고, 새로운 정보를 유통하는 SNS 활동에 대한 인센티브 운영과 행동적 참여로 이끌 수 있는 브랜드 매장 및 서비스 이용 후기 프로모션 등을 고려할 필요가 있다. 일반적으로 적극적인 SNS 활동을 하는 이용자는 많은 정보를 가지고 다른 소비자와 공유하는 성향을 보이며, 입소문의 발신자의 역할을 하는 market maven 성향을 가진다고 추정되므로 긍정적 구전의 활성화를 위해 전략적인 관리를 고려하여야 한다.

셋째, 긍정적 구전의 활성화를 위하여 외식업체의 SNS 고객 관리가 필요하다는 점도 명심해야 한다. 소비자는 기업의 신속하고 진정성 있는 커뮤니케이션을 통해 기업과 원활히 소통하고 있다고 느낀다. 긍정적 구전을 유도하기 위한 혜택 제공 중심의 커뮤니케이션은 단기적으로 긍정적 구전효과를 기대할 수 있으나, 충성도에 긍정적인 영향을 주기 어려우므로 장기적으로 고객 관리 중심의 SNS 마케팅 체계 운영이 필요하다. 또한 브랜드에 대한 적극적 추천과 긍정 구전 활동을 브랜드 매장 방문과 연결시키는 member get member 프로모션은 효과적일 것으로 판단된다.

\section{2. 연구의 한계 및 향후 연구 과제}

본 연구에서는 외식업체 소비자가 이용하는 대중적인 SNS 플랫폼 이용자를 대상으로 SNS 참여와 브랜드에 대한 태도와의 관계를 포괄적으로 분석하였다.

분석 결과에서 SNS 참여는 소비자들의 브랜드 참여를 결정하는 중요한 요소라는 사실이 밝혀졌다. 또한 SNS 활동보다는 구전 활동이 더 영향력이 크다는 점은 많은 시사점을 제공해 줄 수 있다. 그러나 본 연구에서는 SNS 프로모션의 핵심인 SNS 정보품질의 영향력이 명확하지 않은 것으로 나타나 SNS 정보품질의 관리에 대해서는 좀 더 다양한 실증분석이 필요할 것으로 보인다. SNS 사용자들은 SNS 콘텐츠를 
통하여 어떤 정보를 수집하고자 하는지 또한 그러한 정보들을 어떻게 분석하고 활용하는지 등의 구체적인 SNS 정보 활용에 대한 추가적인 연구들이 수행되어야 할 것이다.

한편 향후 연구에서는 SNS 플랫폼이 오픈형, 폐쇄형 또는 텍스트 중심, 이미지, 동영상 중심 등으로 분류가 가능하므로 플랫폼 특성에 따른 SNS 참여의 차이에 대한 연구도 필요할 것으로 보인다. 아울러 외식업 외에 유통업, 제조업 등 SNS 마케팅이 활발한 다른 산업으로 연구의 범위를 확대할 필요가 있으며, 기존 브랜드를 운영하고 있는 기업과 신규 진입하는 기업에 대해서 SNS 참여가 브랜드 태도에 미치는 영향의 차이를 규명할 필요가 있다.

\section{References}

Ahn, J., \& Back, K. J. (2018). Antecedents and consequences of customer brand engagement in integrated resorts. International Journal of Hospitality Management, 75, 144-152.

Algesheimer, R., Dholakia, U. M., \& Herrmann, A. (2005). The social influence of brand community: Evidence from European car clubs. Journal of Marketing, 69(3), 19-34.

Allsop, D. T., Bassett, B. R., \& Hoskins, J. A. (2007). Word-ofmouth research: Principles and applications. Journal of Advertising Research, 47(4), 398-411.

Anderson, E. W. (1998). Customer satisfaction and word of mouth. Journal of Service Research, 1(1), 5-17.

Anderson, W. T., \& Golden, L. L. (1984). Bank promotion strategy. Journal of Advertising Research, 24 (2), 53-65.

Awad, N. F., \& Ragowsky, A. (2008). Establishing trust in electronic commerce through online word of mouth: An examination across genders. Journal of Management Information Systems, 24(4), 101-121.

Babin, B. J., Darden, W. R., \& Griffin, M. (1994). Work and/or fun Measuring hedonic and utilitarian shopping value. Journal of Consumer Research, 20(4), 644-656.

Bagozzi, R. P., \& Dholakia, U. M. (2006a). Open source software user communities: A study of participation in Linux user groups. Management Science, 52(7), 1099-1115.

Bagozzi, R. P., \& Dholakia, U. M. (2006b). Antecedents and purchase consequences of customer participation in small group brand communities. International Journal of Research in Marketing, 23(1), 45-61.

Bansal, H. S., \& Voyer, P. A. (2000). Word-of-mouth processes within a service purchase decision context. Journal of Service Research, 3(2), 166-177.

Barreda, A. A., Bilgihan, A., Nusair, K., \& Okumus, F. (2015). Generating brand awareness in online social networks. Computers in Human Behavior, 50, 600-609.

Bettencourt, L. A. (1997). Customer voluntary performance: Customers as partners in service delivery. Journal of Retailing, 73(3), 383-406.

Bilgihan, A., Peng, C., \& Kandampully, J. (2014). Generation Y's dining information seeking and sharing behavior on social networking sites: An exploratory study. International Journal of Contemporary Hospitality Management, 26(3), 349-366.
Blattberg, R. C., \& Deighton, J. (1991). Interactive marketing: Exploiting the age of addressability. Sloan Management Review, 33(1), 5-15.

Blau, P. M. (1964). Exchange and power in social life. New York, Transaction Publishers.

Brodie, R. J., Hollebeek, L. D., Jurić, B., \& Ilić, A. (2011). Customer engagement: Conceptual domain, fundamental propositions, and implications for research. Journal of Service Research, 14(3), 252-271.

Casaló, L., Flavian, C., \& Guinalíu, M. (2007). The impact of participation in virtual brand communities on consumer trust and loyalty. Online Information Review, 31(6), 775-792.

Cermak, D. S., File, K. M., \& Prince, R. A. (1994). Customer participation in service specification and delivery. Journal of Applied Business Research, 10(2), 90-97.

Chavez, R., Yu, W., Gimenez, C., Fynes, B., \& Wiengarten, F. (2015). Customer integration and operational performance: The mediating role of information quality. Decision Support Systems, 80, 83-95.

Chen, C. J., \& Hung, S. W. (2010). To give or to receive? Factors influencing members' knowledge sharing and community promotion in professional virtual communities. Information \& Management, 47(4), 226-236.

Chen, Y. C., Shang, R. A., \& Li, M. J. (2014). The effects of perceived relevance of travel blogs' content on the behavioral intention to visit a tourist destination. Computers in Human Behavior, 30, 787-799.

Chen, J. S., Tsou, H. T., \& Ching, R. K. (2011). Co-production and its effects on service innovation. Industrial Marketing Management, 40(8), 1331-1346.

Cheng, S., Lam, T., \& Hsu, C. H. (2006). Negative word-of-mouth communication intention: An application of the theory of planned behavior. Journal of Hospitality \& Tourism Research, 30(1), 95-116.

Cheung, C. M., Lee, M. K., \& Rabjohn, N. (2008). The impact of electronic word-of-mouth: The adoption of online opinions in online customer communities. Internet Research: Electronic Networking Applications and Policy, 18(3), 229-247.

Chin, W. W. (1998). The partial least squares approach to structural equation modeling. Modern Methods for Business Research, 295(2), 295-336.

Christophe, V., \& Rimé, B. (1997). Exposure to the social sharing of emotion: Emotional impact, listener responses and secondary social sharing. European Journal of Social Psychology, 27(1), 37-54.

Cohen, J. (1988). Statistical Power Analysis for the Behavioral Sciences, Hilsdale. NJ: Lawrence Earlbaum Associates, 2.

Coulter, K. S., \& Roggeveen, A. (2012). Like it or not. Management Research Review, 35(9), 878-899.

Day, G. S. (1971). Attitude change, media and word of mouth. Journal of Advertising Research, 11(6), 31-40.

De Choudhury M. (2011) Information Quality and Relevance in Large-Scale Social Information Systems. In: Furht B., Escalante A. (eds). Handbook of Data Intensive Computing. Springer, New York, NY

Dellarocas, C. (2003). The digitization of word of mouth: Promise and challenges of online feedback mechanisms. Management Science, 49(10), 1407-1424. 
DeLone, W. H., \& McLean, E. R. (1992). Information systems success: The quest for the dependent variable. Information Systems Research, 3(1), 60-95.

Delone, W. H., \& McLean, E. R. (2003). The DeLone and McLean model of information systems success: A ten-year update. Journal of Management Information Systems, 19(4), 930 .

Dessart, L., Veloutsou, C., \& Morgan-Thomas, A. (2015). Consumer engagement in online brand communities: A social media perspective. Journal of Product \& Brand Management, 24(1), 28-42.

De Vries, L., Gensler, S., \& Leeflang, P. S. (2012). Popularity of brand posts on brand fan pages: An investigation of the effects of social media marketing. Journal of Interactive Marketing, 26(2), 83-91.

Dholakia, U. M., Bagozzi, R. P., \& Pearo, L. K. (2004). A social influence model of consumer participation in network-and small-group-based virtual communities. International Journal of Research in Marketing, 21(3), 241-263.

Dholakia, U. M., Blazevic, V., Wiertz, C., \& Algesheimer, R. (2009). Communal service delivery: How customers benefit from participation in firm-hosted virtual P3 communities. Journal of Service Research, 12(2), 208-226.

Dijkmans, C., Kerkhof, P., \& Beukeboom, C. J. (2015). A stage to engage: Social media use and corporate reputation. Tourism Management, 47, 58-67.

DiPietro, R. B., Crews, T. B., Gustafson, C., \& Strick, S. (2012). The use of social networking sites in the restaurant industry: Best practices. Journal of Foodservice Business Research, 15(3), 265-284.

Eisingerich, A. B., Auh, S., \& Merlo, O. (2014). Acta non verba? The role of customer participation and word of mouth in the relationship between service firms' customer satisfaction and sales performance. Journal of Service Research, 17(1), 40-53.

Falk, R. F. and N. Miller (1992). A primer for soft modeling, Akron, Ohio: University of Akron Press.

Fang, E. (2008). Customer participation and the trade-off between new product innovativeness and speed to market. Journal of Marketing, 72(4), 90-104.

Ferguson, R. (2008). Word of mouth and viral marketing: Taking the temperature of the hottest trends in marketing. Journal of Consumer Marketing, 25(3), 179-182.

File, K.M. \& Prince R. A. (1992). Positive of-mouth: Customer satisfaction and buyer behavior. International Journal of Bank Marketing, 10(1), 25-29.

Fornell, C., \& Larcker, D. F. (1981). Evaluating structural equation models with unobservable variables and measurement error. Journal of Marketing Research, 18(1), 39-50.

Fornell, C., \& Wernerfelt, B. (1987). Defensive marketing strategy by customer complaint management: A theoretical analysis. Journal of Marketing Research, 24(4), 337-346.

Ghasemaghaei, M., \& Hassanein, K. (2015). Online information quality and consumer satisfaction: The moderating roles of contextual factors-A meta-analysis. Information \& Management, 52(8), 965-981.

Gorla, N., Somers, T. M., \& Wong, B. (2010). Organizational impact of system quality, information quality, and service quality. Journal of Strategic Information Systems, 19(3), 207228.
Grewal, R., Cline, T. W., \& Davies, A. (2003). Early-entrant advantage, word-of-mouth communication, brand similarity, and the consumer decision-making process. Journal of Consumer Psychology, 13(3), 187-197.

Gutiérrez, S. S., Cillán, J. G., \& Izquierdo, C. C. (2004). The consumer's relational commitment: main dimensions and antecedents. Journal of Retailing and Consumer Services, 11(6), 351-367.

Hair, J. F., Hult, G. T. M., Ringle, C., \& Sarstedt, M. (2017). A primer on partial least squares structural equation modeling (PLS-SEM). Thousand Oaks, CA: Sage Publications.

Harmeling, C. M., Moffett, J. W., Arnold, M. J. \& Carlson, B. D. (2016), Toward a theory of customer engagement marketing, Journal of the Academy of Marketing Science, 45(3), 312-335.

Hennig-Thurau, T., Gwinner, K. P., Walsh, G., \& Gremler, D. D. (2004). Electronic word-of-mouth via consumer-opinion platforms: what motivates consumers to articulate themselves on the internet? Journal of Interactive Marketing, 18(1), 38-52.

Henseler, J., Ringle, C. M., \& Sarstedt, M. (2015). A new criterion for assessing discriminant validity in variance-based structural equation modeling. Journal of the Academy of Marketing Science, 43(1), 115-135.

Hollebeek, L. D. (2011). Demystifying customer brand engagement: Exploring the loyalty nexus. Journal of Marketing Management, 27(7-8), 785-807.

Hollebeek, L. D., Glynn, M. S., \& Brodie, R. J. (2014). Consumer brand engagement in social media: Conceptualization, scale development and validation. Journal of Interactive Marketing, 28(2), 149-165.

Hsu, L. C., Wang, K. Y., \& Chih, W. H. (2018). Investigating virtual community participation and promotion from a social influence perspective. Industrial Management \& Data Systems, $118(6), 1229-1250$.

Huang, M. H., 2003. Web performance scale. Information \& Management, 42(6), 841-852.

Islam, J. U., \& Rahman, Z. (2017). The impact of online brand community characteristics on customer engagement: An application of Stimulus-Organism-Response paradigm. Telematics and Informatics, 34(4), 96-109.

Jang, H., Olfman, L., Ko, I., Koh, J., \& Kim, K. (2008). The influence of on-line brand community characteristics on community commitment and brand loyalty. International Journal of Electronic Commerce, 12(3), 57-80.

Kang, B. S., Yang J. J., \& Lee, S. D.(2018). Effects of information sources on enjoyment, attitude, and visit intention in restaurant, Korean Journal of Franchise Management, 9(3), 7-18.

Kaplan, A. M., \& Haenlein, M. (2010). Users of the world, unite! The challenges and opportunities of Social Media. Business Horizons, 53(1), 59-68.

Katz, E., \& Lazarsfeld, P. F. (1955). Personal influence, ed. Vol. 2, Foundations in Communications Research. New York: The Free Press.

Keller, E. (2007). Unleashing the power of word of mouth: Creating brand advocacy to drive growth. Journal of Advertising Research, 47(4), 448-452.

Keller, K. (2013). Strategic brand management: Global edition. Pearson Higher Ed.

Keller, K. L. (2003). Strategic Brand Management: Building, Measuring, and Managing Brand Equity. Upper Saddle River, NJ: Pearson Education International. 
Keller, E., \& Fay, B. (2009). The role of advertising in word of mouth. Journal of Advertising Research, 49(2), 154-158.

Kim, J. H., Bae, Z. T., \& Kang, S. H. (2008). The role of online brand community in new product development: Case studies on digital product manufacturers in Korea. International Journal of Innovation Management, 12(3), 357-376.

Kim, H. S., Choi, Y. S., \& Shin, C. S. (2019). Relationship among restaurant owner's SNS marketing, trust, purchase intention, and word of mouth intention. Journal of Distribution Science, 17(7), 27-38.

Kim, S., Koh, Y., Cha, J., \& Lee, S. (2015). Effects of social media on firm value for US restaurant companies. International Journal of Hospitality Management, 49, 40-46.

Kim, S. E., Lee, K. Y., Shin, S. I., \& Yang, S. B. (2017). Effects of tourism information quality in social media on destination image formation: The case of Sina Weibo. Information \& Management, 54(6), 687-702.

Kim, H., \& Song, J. (2010). The quality of word-of-mouth in the online shopping mall. Journal of Research in Interactive Marketing, 4(4), 376-390.

Koh, J., \& Kim, Y. G. (2004). Knowledge sharing in virtual communities: An e-business perspective. Expert Systems with Applications, 26(2), 155-166.

Koohikamali, M., \& Sidorova, A. (2017). Information re-sharing on social network sites in the age of fake news. Informing Science, 20, 215-235.

Kwok, L., \& Yu, B. (2013). Spreading social media messages on Facebook: An analysis of restaurant business-to-consumer communications. Cornell Hospitality Quarterly, 54(1), 84-94.

Lang, B., \& Hyde, K. F. (2013). Word of mouth: What we know and what we have yet not learn. Journal of Consumer Satisfaction, Dissatisfaction \& Complaining Behavior, 26, 118.

Larson, A. (1992). Network dyads in entrepreneurial settings: A study of the governance of exchange relationships. Administrative Science Quarterly, 37(1), 76-104.

Lee,Y-K., Jeong, Y. K. \& Yoo, D. K.(2008). determinants of relationship commitment: Relational benefits, core quality, and relationship satisfaction. The Academy of Customer Satisfaction Management, 10(1), 51-69.

Lee, J. Y., Lee, M. J., Kwon, D. J., Jeong, S. Y., \& Hur, S. B. (2019). Impacts of food service franchise's SNS marketing activities on customer behavior intention, Korean Journal of Franchise Management, 10(1), 43-52.

Lee, M., \& Youn, S. (2009). Electronic word of mouth (eWOM) How eWOM platforms influence consumer product judgement. International Journal of Advertising, 28(3), 473499.

Leung, X. Y., Bai, B., \& Stahura, K. A. (2015). The marketing effectiveness of social media in the hotel industry: A comparison of Facebook and Twitter. Journal of Hospitality \& Tourism Research, 39(2), 147-169.

Lim, J. S., Hwang, Y., Kim, S., \& Biocca, F. A. (2015). How social media engagement leads to sports channel loyalty: Mediating roles of social presence and channel commitment. Computers in Human Behavior, 46, 158-167.

Lin, K. Y., \& Lu, H. P. (2011). Intention to continue using Facebook fan pages from the perspective of social capital theory. Cyberpsychology, Behavior, and Social Networking, 14(10), 565-570.

Liu, Y. (2006). Word of mouth for movies: Its dynamics and impact on box office revenue. Journal of Marketing, 70(3), 7489.

Lundeen, H. K., Harmon, L. C., \& McKenna-Harmon, K. M. (1995). Service recovery in commercial real estate management. Journal of Property Management, 60(3), 30-33.

Lutz, R. J., \& Reilly, P. J. (1973). An exploration of the effects of perceived social and performance risk on consumer information acquisition. Advances in Consumer Research, 1, 393-405.

Macey, W. H., \& Schneider, B. (2008). The meaning of employee engagement. Industrial and Organizational Psychology, 1(1), 3-30.

Manchanda, P., Xie, Y., \& Youn, N. (2008). The role of targeted communication and contagion in product adoption. Marketing Science, 27(6), 961-976.

Mancini J.A., Martin J.A., Bowen G.L. (2003). Community capacity. In: Gullotta T.P. et al. (eds). Encyclopedia of Primary Prevention and Health Promotion. Springer, Boston, MA

Martins, C. S., \& Patrício, L. (2013). Understanding participation in company social networks. Journal of Service Management, 24(5), 567-587.

Maxham III, J. G. (2001). Service recovery's influence on consumer satisfaction, positive word-of-mouth, and purchase intentions. Journal of Business Research, 54(1), 11-24.

McEwen, W. (2004). Why satisfaction isn't satisfying. Gallup Management Journal Online, 11, 1-4.

Men, L. R., \& Tsai, W. H. S. (2013). Toward an integrated model of public engagement on corporate social networking sites: Antecedents, the process, and relational outcomes. International Journal of Strategic Communication, 7(4), 257-273.

Men, L. R., \& Tsai, W. H. S. (2014). Perceptual, attitudinal, and behavioral outcomes of organization-public engagement on corporate social networking sites. Journal of Public Relations Research, 26(5), 417-435.

Men, L. R., \& Tsai, W. H. S. (2015). Infusing social media with humanity: Corporate character, public engagement, and relational outcomes. Public Relations Review, 41(3), 395-403.

Meuter, M. L., McCabe, D. B., \& Curran, J. M. (2013). Electronic word-of-mouth versus interpersonal word-of-mouth: are all forms of word-of-mouth equally influential? Services Marketing Quarterly, 34(3), 240-256.

Miller, H. (1996). The multiple dimensions of information quality. Information Systems Management, 13(2), 79-82.

Mizerski, R. W. (1982). An attribution explanation of the disproportionate influence of unfavorable information. Journal of Consumer Research, 9(3), 301-310.

Moore, R., Moore, M. L., \& Capella, M. (2005). The impact of customer-to-customer interactions in a high personal contact service setting. Journal of Services Marketing, 19 (7), 482-491.

Muntinga, D. G., Moorman, M., \& Smit, E. G. (2011). Introducing COBRAs: Exploring motivations for brand-related social media use. International Journal of Advertising, 30(1), 13-46.

Nahapiet, J., \& Ghoshal, S. (1998). Social capital, intellectual capital, and the organizational advantage. Academy of Management Review, 23(2), 242-266. 
Nguyen, V., \& Bang, J. H. (2019). E-tailing \& Brand Communication in Facebook: Comparing Germans and Koreans. Journal of Distribution Science, 17(8), 99-106.

Nicolaou, A. I., Ibrahim, M., \& Van Heck, E. (2013). Information quality, trust, and risk perceptions in electronic data exchanges. Decision Support Systems, 54(2), 986-996.

Pai, P. Y., \& Tsai, H. T. (2011). How virtual community participation influences consumer loyalty intentions in online shopping contexts: an investigation of mediating factors. Behaviour \& Information Technology, 30(5), 603-615.

Phelps, J. E., Lewis, R., Mobilio, L., Perry, D., \& Raman, N. (2004). Viral marketing or electronic word-of-mouth advertising: Examining consumer responses and motivations to pass along email. Journal of Advertising Research, 44(4), 333348.

Reinartz, W. J., \& Kumar, V. (2000). On the profitability of longlife customers in a noncontractual setting: An empirical investigation and implications for marketing. Journal of Marketing, 64(4), 17-35.

Reinartz, W., \& Kumar, V. (2002). The mismanagement of customer loyalty. Harvard Business Review, 80(7), 86.

Richins, M. L., \& Root-Shaffer, T. (1987). The role of evolvement and opinion leadership in consumer word-of-mouth: An implicit model made explicit. In Advances in Consumer Research, ed. Michael J. Houston, Association for Consumer Research, 32-36.

Ring, P. S., \& Van de Ven, A. H. (1994). Developmental processes of cooperative interorganizational relationships. Academy of Management Review, 19(1), 90-118.

Rohm, A., Kaltcheva, V. D., \& Milne, G. R. (2013). A mixedmethod approach to examining brand-consumer interactions driven by social media. Journal of Research in Interactive Marketing, 7(4), 295-311.

Ryu, G., \& Feick, L. (2007). A penny for your thoughts: Referral reward programs and referral likelihood. Journal of Marketing, 71(1), 84-94.

Sashi, C. M. (2012). Customer engagement, buyer-seller relationships, and social media. Management Decision, 50(2), 253-272.

Schau, H. J., Muñiz Jr, A. M., \& Arnould, E. J. (2009). How brand community practices create value. Journal of Marketing, 73(5), $30-51$.

Schmitt, P., Skiera, B., \& Van den Bulte, C. (2011). Referral programs and customer value. Journal of Marketing, 75(1), 46-59.

Sheth, J. N. (1971). Word-of-mouth in low-risk innovations. Journal of Advertising, 11, 15-18.

Shin, Y. H., \& Kim, S. G. (2017). Comparative analyses of social media on its impacts on consumer behavior in on-line markets. Journal of Distribution Science, 15(10), 81-92.

Sparks, B. A., \& Bradley, G. L. (2017). A "Triple A" typology of responding to negative consumer-generated online reviews. Journal of Hospitality \& Tourism Research, 41(6), 719-745.

Steffes, E. M., \& Burgee, L. E. (2009). Social ties and online word of mouth. Internet Research, 19(1), 42-59.

Stokes, D. (1997). A lesson in entrepreneurial marketing from the public sector. Marketing Education Review, 7(3), 47-54.

Stromer-Galley, J. (2000). On-line interaction and why candidates avoid it. Journal of communication, 50(4), 111-132.
Sullivan, C. (1999). Marketing the Web in other media. Editor \& Publisher, 132(9), 30-30.

Sultan, F., Farley, J. U., \& Lehmann, D. R. (1990). A metaanalysis of applications of diffusion models. Journal of Marketing Research, 27(1), 70-77.

Swan, J. E., \& Oliver, R. L. (1989). Postpurchase communications by consumers. Journal of Retailing, 65(4), 516-533.

Sweeney, J. C., Soutar, G. N., \& Mazzarol, T. (2008). Factors influencing word of mouth effectiveness: Receiver perspectives. European Journal of Marketing, 42(3/4), 344364.

Tafesse, W., \& Wien, A. (2018). Using message strategy to drive consumer behavioral engagement on social media. Journal of Consumer Marketing, 35(3), 241-253.

Touni, R., Kim, W. G., Choi, H. M., \& Ali, M. A. (2019). Antecedents and outcome of customer engagement with hotel brand community on Facebook. Journal of Hospitality \& Tourism Research, 44(2), 278-299.

Trusov, M., Bucklin, R. E., \& Pauwels, K. (2009). Effects of word-of-mouth versus traditional marketing: Findings from an internet social networking site. Journal of Marketing, 73(5), 90-102.

Van der Heijden, H. (2004). User acceptance of hedonic information systems. MIS Quarterly, 28(4), 695-704.

Van Doorn, J., Lemon, K. N., Mittal, V., Nass, S., Pick, D., Pirner, P., \& Verhoef, P. C. (2010). Customer engagement behavior: Theoretical foundations and research directions. Journal of Service Research, 13(3), 253-266.

Varey, R. J. (2008). Marketing as an interaction system. Australasian Marketing Journal16(1), 79-94.

Vivek, S. D., Beatty, S. E., \& Morgan, R. M. (2012). Customer engagement: Exploring customer relationships beyond purchase. Journal of Marketing Theory and Practice, 20(2), 122-146.

Vivek, S. D., Beatty, S. E., Dalela, V., \& Morgan, R. M. (2014). A generalized multidimensional scale for measuring customer engagement. Journal of Marketing Theory and Practice, 22(4), 401-420.

Von Hippel, E. (2009). Democratizing innovation: the evolving phenomenon of user innovation. International Journal of Innovation Science, 1(1), 29-40.

Wand, Y., \& Wang, R. Y. (1996). Anchoring data quality dimensions in ontological foundations. Communications of the ACM, 39(11), 86-95.

Wang, E. S. T., \& Chen, L. S. L. (2012). Forming relationship commitments to online communities: The role of social motivations. Computers in Human Behavior, 28(2), 570-575.

Wang, R. Y., \& Strong, D. M. (1996). Beyond accuracy: What data quality means to data consumers. Journal of Management Information Systems, 12(4), 5-33.

Wangenheim, F. V., \& Bayón, T. (2004). The effect of word of mouth on services switching. European Journal of Marketing, 38(9/10), 1173-1185.

Wangenheim, F. V., \& Bayón, T. (2007). The chain from customer satisfaction via word-of-mouth referrals to new customer acquisition. Journal of the Academy of Marketing Science, 35(2), 233-249.

Watts, S. A., \& Zhang, W. (2008). Capitalizing on content: Information adoption in two online communities. Journal of the Association for Information Systems, 9(2), 73-94. 
Webster, C. (1991). Influences upon consumer expectations of services. Journal of Services Marketing, 5 (Winter), 5-17.

Whiting, A., \& Williams, D. (2013). Why people use social media: a uses and gratifications approach. Qualitative Market Research, 16(4), 362-369.

Wirtz, J., den Ambtman, A., Bloemer, J., Horváth, C., Ramaseshan, B., van de Klundert, J., Gurhan Canli, Z. and Kandampully, J. (2013), "Managing brands and customer engagement in online brand communities", Journal of Service Management, 24(3), 223-244.

Wixom, B. H., \& Todd, P. A. (2005). A theoretical integration of user satisfaction and technology acceptance. Information Systems Research, 16(1), 85-102.

Woisetschläger, D. M., Hartleb, V., \& Blut, M. (2008). How to make brand communities work: Antecedents and consequences of consumer participation. Journal of Relationship Marketing, 7(3), 237-256.

Yang, K., Li, X., Kim, H., \& Kim, Y. H. (2015). Social shopping website quality attributes increasing consumer participation, positive eWOM, and co-shopping: The reciprocating role of participation. Journal of Retailing and Consumer Services, 24, $1-9$.

Yang, S., Liu, Y., \& Wei, J. (2016). Social capital on mobile SNS addiction. Internet Research, 26(4), 982-1000.
Yu, Y. T., \& Dean, A. (2001). The contribution of emotional satisfaction to consumer loyalty. International Journal of Service Industry Management, 12(3), 234-250.

Zeithaml, V. A., Berry, L. L., \& Parasuraman, A. (1993). The nature and determinants of customer expectations of service. Journal of the Academy of Marketing Science, 21(1), $1-12$.

Zhang, C. B., Li, Y. N., Wu, B., \& Li, D. J. (2017). How WeChat can retain users: Roles of network externalities, social interaction ties, and perceived values in building continuance intention. Computers in Human Behavior, 69, 284-293.

Zheng, X., Cheung, C. M., Lee, M. K., \& Liang, L. (2015). Building brand loyalty through user engagement in online brand communities in social networking sites. Information Technology \& People, 28(1), 90-106.

Zheng, Y., Zhao, K., \& Stylianou, A. (2013). The impacts of information quality and system quality on users' continuance intention in information-exchange virtual communities: An empirical investigation. Decision Support Systems, 56, 513524.

Zhou, T., Li, H., \& Liu, Y. (2010). The effect of flow experience on mobile SNS users' loyalty. Industrial Management \& Data Systems, 110(6), 930-946.

Zmud, R. W. (1978). An empirical investigation of the dimensionality of the concept of information. Decision Sciences, 9(2), 187-195. 


\section{Appendixes}

Appendix 1: Measurement Model

\begin{tabular}{|c|c|c|c|c|}
\hline Items & $\begin{array}{l}\text { Standardized } \\
\text { factor loadings }\end{array}$ & $C R^{a}$ & $\mathrm{AVE}^{\mathrm{b}}$ & Cronbach $\alpha$ \\
\hline SNS information quality characteristics & & 0.866 & 0.568 & 0.829 \\
\hline The information provided by food service brand SNS is reliable & 0.747 & & & \\
\hline The information provided by brand SNS is complete & 0.841 & & & \\
\hline The information provided by food service brand SNS is accurate & 0.709 & & & \\
\hline The information provided by food service brand SNS is up to date. & 0.606 & & & \\
\hline The information provided by food service brand SNS is what I need. & 0.840 & & & \\
\hline SNS hedonic characteristics & & 0.897 & 0.686 & 0.847 \\
\hline The information provided by food service brand SNS is pleasant & 0.848 & & & \\
\hline The information provided by food service brand SNS is fun. & 0.823 & & & \\
\hline The information provided by food service brand SNS is entertaining & 0.852 & & & \\
\hline The information provided by food service brand SNS is exciting & 0.788 & & & \\
\hline SNS interaction characteristics & & 0.970 & 0.889 & 0.958 \\
\hline $\begin{array}{c}\text { I engage in a high level of interaction with friends using food service } \\
\text { brand SNS }\end{array}$ & 0.942 & & & \\
\hline $\begin{array}{l}\text { I spend considerable time interacting with some members in brand } \\
\text { SNS }\end{array}$ & 0.933 & & & \\
\hline $\begin{array}{l}\text { I have frequent communication with some members in the food service } \\
\text { brand SNS }\end{array}$ & 0.952 & & & \\
\hline $\begin{array}{l}\text { I maintain close online relationships with some members in food } \\
\text { service brand SNS }\end{array}$ & 0.944 & & & \\
\hline SNS engagement - Participation & & 0.904 & 0.653 & 0.867 \\
\hline I leave posts on the food service brand SNS & 0.816 & & & \\
\hline I post my comments on the food service brand SNS & 0.838 & & & \\
\hline I join events organized through the food service brand SNS & 0.757 & & & \\
\hline I ask and answer questions on the food service brand SNS & 0.858 & & & \\
\hline $\begin{array}{l}\text { I help other people by providing them with information about the } \\
\text { product/brand on the food service brand SNS }\end{array}$ & 0.766 & & & \\
\hline SNS engagement - Positive WOM & & 0.909 & 0.714 & 0.866 \\
\hline I actively invite my close acquaintances to join food service brand SNS & 0.832 & & & \\
\hline I often introduce my peers or friends to food service brand SNS & 0.902 & & & \\
\hline I recommend the food service brand SNS to my friend & 0.817 & & & \\
\hline I often talk to people about benefit of the food service brand SNS & 0.826 & & & \\
\hline Behavioral engagement & & 0.905 & 0.761 & 0.843 \\
\hline I use this food service brand the most & 0.852 & & & \\
\hline $\begin{array}{c}\text { I spent a lot of time using this food service brand compared with other } \\
\text { brand }\end{array}$ & 0.883 & & & \\
\hline $\begin{array}{c}\text { Whenever I'm using food service brand, I usually use this food service } \\
\text { brand }\end{array}$ & 0.881 & & & \\
\hline
\end{tabular}

aCR(Composite Reliability), bAVE(Average Variance Extracted) 
Appendix 2: Fornell-Larcker Criterion and Correlation Matrix

\begin{tabular}{|c|c|c|c|c|c|c|}
\hline & $\mathbf{1}$ & $\mathbf{2}$ & $\mathbf{3}$ & $\mathbf{4}$ & $\mathbf{5}$ & $\mathbf{6}$ \\
\hline SNS information quality & 0.754 & & & & & \\
\hline SNS hedonic & 0.631 & 0.828 & & & & \\
\hline SNS interaction & 0.029 & 0.203 & 0.943 & & & \\
\hline SNS participation & 0.226 & 0.361 & 0.666 & 0.808 & & \\
\hline Positive WOM & 0.254 & 0.400 & 0.565 & 0.710 & 0.845 & 0.380 \\
\hline Behavioral engagement & 0.323 & 0.316 & 0.320 & 0.362 & 0.872 \\
\hline
\end{tabular}

Appendix 3: Heterotrait-Monotrait Ratio (HTMT)

\begin{tabular}{|c|c|c|c|c|c|c|}
\hline & 1 & 2 & 3 & 4 & 5 & 6 \\
\hline SNS information quality & 1 & & & & & \\
\hline SNS hedonic & 0.734 & 1 & & & & \\
\hline SNS interaction & 0.164 & 0.220 & 1 & & & \\
\hline SNS participation & 0.253 & 0.421 & 0.720 & 1 & & \\
\hline Positive WOM & 0.269 & 0.467 & 0.609 & 0.812 & 1 & \\
\hline Behavioral engagement & 0.385 & 0.374 & 0.356 & 0.426 & 0.440 & 1 \\
\hline
\end{tabular}

Bold numbers indicate the square root of $A$

Appendix 4: Structural Estimates(PLS)

\begin{tabular}{|c|c|c|c|c|c|c|c|}
\hline & Paths & Estimate & \multicolumn{2}{|c|}{ t-value } & $\mathbf{p}$ & $f^{2}$ & Results \\
\hline H1-1 & SNS information quality $\rightarrow$ SNS participation & 0.100 & 2.184 & $*$ & 0.029 & 0.012 & Supported \\
\hline $\mathrm{H} 1-2$ & SNS information quality $\rightarrow$ Positive WOM & 0.035 & 0.763 & & 0.445 & 0.002 & Non-supported \\
\hline $\mathrm{H} 2-1$ & SNS hedonic $\rightarrow$ SNS participation & 0.170 & 3.541 & $* * *$ & 0.000 & 0.033 & Supported \\
\hline $\mathrm{H} 2-2$ & SNS hedonic $\rightarrow$ Positive WOM & 0.150 & 2.962 & $* *$ & 0.003 & 0.027 & Supported \\
\hline $\mathrm{H} 3-1$ & SNS interaction $\rightarrow$ SNS participation & 0.628 & 21.648 & $* * *$ & 0.000 & 0.746 & Supported \\
\hline $\mathrm{H} 3-2$ & SNS interaction $\rightarrow$ Positive WOM & 0.183 & 3.548 & $* * *$ & 0.000 & 0.040 & Supported \\
\hline $\mathrm{H} 4$ & SNS participation $\rightarrow$ Positive WOM & 0.526 & 9.899 & $* * *$ & 0.000 & 0.304 & Supported \\
\hline H5 & SNS participation $\rightarrow$ Behavioral engagement & 0.185 & 2.737 & $* *$ & 0.006 & 0.020 & Supported \\
\hline \multirow[t]{5}{*}{ H6 } & Positive WOM $\rightarrow$ Behavioral engagement & 0.249 & 3.532 & $* * *$ & 0.000 & 0.037 & Supported \\
\hline & & \multicolumn{4}{|c|}{$R^{2}$} & \multicolumn{2}{|c|}{$Q^{2}$} \\
\hline & SNS participation & \multicolumn{4}{|c|}{0.502} & \multicolumn{2}{|c|}{0.322} \\
\hline & Positive WOM & \multicolumn{4}{|c|}{0.546} & \multicolumn{2}{|c|}{0.380} \\
\hline & Behavioral commitment & \multicolumn{4}{|c|}{0.161} & \multicolumn{2}{|c|}{0.119} \\
\hline
\end{tabular}

${ }^{* \star *} p<0.001{ }^{* *} p<0.01 ;{ }^{*} p<0.05$

Appendix 5: Mediation Test Using Bootstrapping

\begin{tabular}{|l|c|c|c|}
\hline \multicolumn{1}{|c|}{ Paths of mediating role } & Direct effect(t-value) & Indirect effect(t-value) & Mediating Role \\
\hline SNS information quality $\rightarrow$ SNS participation $\rightarrow$ Positive WOM & $0.035(0.763)$ & $0.053(2.107)^{*}$ & Full mediator $^{*}$ \\
\hline SNS hedonic level $\rightarrow$ SNS participation $\rightarrow$ Positive WOM & $0.150(2.962)^{* *}$ & $0.089(3.367)^{* *}$ & Partial mediator \\
\hline SNS interaction $\rightarrow$ SNS participation $\rightarrow$ Positive WOM & $0.183(3.548)^{* * *}$ & $0.331(8.727)^{* * *}$ & Partial mediator \\
\hline SNS participation $\rightarrow$ Positive WOM $\rightarrow$ Behavioral engagement & $0.185(2.737)^{* *}$ & $0.131(3.534)^{* * *}$ & Partial mediator \\
\hline
\end{tabular}

${ }^{* * *} p<0.001,{ }^{* *} p<0.01,{ }^{*} p<0.05$ 